\title{
Attachment and Emotion Processing in Children with Autism Spectrum Disorders: Neurobiological, Neuroendocrine, and Neurocognitive Considerations
}

\author{
Carmel S. Sivaratnam ${ }^{1}$ • Louise K. Newman ${ }^{2}$ • Bruce J. Tonge ${ }^{3}$. \\ Nicole J. Rinehart ${ }^{4}$
}

Received: 13 November 2014 / Accepted: 28 March 2015/Published online: 15 April 2015

(C) Springer Science+Business Media New York 2015

\begin{abstract}
The understanding, expression, and regulation of emotion have been identified as core to everyday communication and psychosocial adjustment in children. The aim of this paper is to review and to compare current clinical and empirical knowledge on emotion recognition, reciprocity, and expression deficits in children diagnosed with autism spectrum disorders (ASD). The paper reviews current neurobiological, neuroendocrine, and neurocognitive explanations for the emotion-processing deficits seen in ASD, while considering the potential influence of attachment on the presentation of emotion-processing deficits seen in this disorder, which is characterised by organic emotion-processing deficits. This review adopts a multi-disciplinary approach, proposing that in order to further compound the established organic explanations for emotion-processing deficits in ASD, more investigations are warranted to delineate the specific impact that attachment orientations have on the inability to appropriately recognise and regulate emotion in this disorder. Further research is required to improve our understanding of the neural processes which underlie emotion-processing abilities in the context of parent-child developmental factors.
\end{abstract}

Carmel S. Sivaratnam

Carmel.Sivaratnam@monash.edu

1 School of Psychological Sciences, Monash University, Wellington Road, Clayton, Victoria 3800, Australia

2 Department of Psychiatry, University of Melbourne, Parkville, Victoria 3010, Australia

3 Centre for Developmental Psychiatry and Psychology, Monash University, Clayton, Victoria 3800, Australia

4 School of Psychology, Deakin University, 221 Burwood Highway, Burwood, Victoria 3125, Australia
Keywords Emotion processing $\cdot$ Attachment $\cdot$ Autism spectrum disorders $\cdot$ Theory of mind

The ability to understand, express, and regulate emotion appropriately has been long identified as core to everyday communication and social interaction in children regardless of intellectual, developmental, or cultural background (Elfenbein and Ambady 2002; Herba et al. 2006). Emotion processing is currently conceptualised as the encompassing ability to not only perceive and infer others' and one's own emotional states (Lipton and Nowicki 2009; Bauminger 2002; Ochsner and Gross 2005), but in regulating one's own emotional states and behaviour to express emotion or respond appropriately to interpersonal interactions (Lipton and Nowicki 2009; Beauchamp and Anderson 2010; Konstantareas and Stewart 2006; Lee and Hoaken 2007). While attachment has been found to be an important factor in facilitating the developing child's ability to understand, express, and regulate emotion appropriately in typicallydeveloping (TD) children (Zeanah et al. 2002; Schore 2009; Rieffe et al. 2011), there is a lack of research investigating the role of attachment in emotion-processing outcomes in children with autism spectrum disorders (ASD), an increasingly prevalent disorder which has a significant impact on communication and social interaction. Far more research has been undertaken to understand the neurological or neurobiological phenotype of ASD (Corbett et al. 2008; Corbett et al. 2006; Dawson et al. 2002, 2004; Dawson 2008). Sparked by early explorations into facial emotion processing in ASD, such as those of Hobson and colleagues $(1986,1987,1989,1998)$, neurobiological research has contributed to the further definition of the phenotype and the neurological underpinnings of emotion processing in ASD using methods such as transcranial 
magnetic stimulation (Enticott et al. 2010), functional magnetic resonance imaging (Harris et al. 2006), and EEG (Murias et al. 2007). While this research is leading to important discoveries about the possible neurological underpinnings of emotion processing in ASD, understanding the influence of environmental factors such as attachment on the organic emotion-processing deficits seen early on in ASD will be important in developing an integrative model of emotion-processing deficits in children with ASD that goes beyond the diagnostic label.

There are several historical and scientific factors which are likely to contribute to the current state of ASD research, where little is known about integration of environmental and biological factors influencing emotion-processing deficits. Firstly, the last few decades have seen a backlash to the notorious claim of 'refrigerator' parenting (Bishop et al. 2004; Cantwell et al. 1976), specifically that the parent's inability to emotionally engage with the child could account for the child's autistic behaviour, placing unwarranted stigma, and blame on the parents of children with ASD (Bettelheim 1967). One major contribution to the breakdown of the stigma on environmental contributions to emotion-processing deficits in ASD is recognition of a genetic basis for this disorder (Piggot et al. 2009), which consequently negated theories such as 'refrigerator' parenting as contributing to ASD.

In addition to theories such as the 'refrigerator' parent theory, there have been several other environmentally-based theories which have since scientifically investigated and strongly refuted, for example, the controversial findings linking vaccines and autism (Megson 2000; Wakefield 1998), which suggested that ASD is caused by environmental preservatives, toxins and antigens from vaccines, as well as encephalopathy following vaccinations in young children (see Ratajczak (2011) for a review). These theories have been strongly refuted by scientific and empirical findings as factors contributing to ASD (Kennedy and Lawrence 2011). Similarly, there has been strong empirical negation for the suspected role of environmental neurotoxins such as mercury (Kempuraj et al. 2010) in contributing to ASD (Ip et al. 2004) in the development of ASD.

While neurobiological and behavioural research is beginning to shed light on the phenotype and neurological underpinnings of emotion-processing deficits in ASD, the gap in the understanding of the role of environmental factors in the development of emotion-processing abilities of children with ASD has prevented a holistic conceptualisation of the aetiology of these deficits. Whereas studies of TD children have linked attachment security to lower levels of emotion-processing impairments, it is likely that the relationship between attachment and emotionprocessing abilities in ASD groups may involve a more complex interplay of factors, in light of the organic emotion-processing deficits seen early on in ASD, within the first year of life (Garon et al. 2009; Yirmiya et al. 1989; Adamson et al. 2001). Particularly, while empirical studies have consistently shown that ASD is a neurodevelopmental disorder with organic impairments in emotion recognition, understanding, and regulation, little is known about the interaction between these organic impairments and attachment relationships in the presentation of emotion-processing impairments in ASD. In TD groups, early attachment disruptions, particularly, in the formation of disorganised and/or insecure attachments (Chugani et al. 2001), have been found to alter particular brain regions (De Bellis and Kuchibhatla 2006; Strathearn 2007) implicated in emotional knowledge (Maughan and Cicchetti 2002) and regulation (Bolger and Patterson 2003). Current theoretical and empirical notions conceptualise the attachment relationship as bidirectional, that is, influenced by the individual characteristics and interactions of both the caregiver and the child (Jones and Schwartz 2009; DoussardRoosevelt et al. 2003). This notion, together with the findings that the deficits in reciprocal social interaction and engagement that infants and children demonstrate in ASD (Adamson et al. 2001) influence the responses of caregivers (Doussard-Roosevelt et al. 2003), indicates that there is a need for research to explore the nature and correlates of attachment relationships in ASD, a disorder in which pre-existing socio-emotional deficits have been found to influence the characteristics of the developing attachment relationship. Moreover, given the influence of attachment security on subsequent positive biopsychosocial outcomes in childhood and adulthood, the influence of early attachment is an area warranting exploration in relation to its contributions to overall socio-emotional functioning and mental health outcomes for individuals with ASD.

Thus, the aim of this review is to bring together current knowledge on emotion processing in children with ASD, particularly, how neurogenetic factors shape emotionprocessing deficits in ASD and what we know about the role of attachment factors. This will be achieved by (a) a review of the current empirical emotion-processing studies of children with ASD, specifically in emotion recognition and regulation, and (b) a review of current findings on the neuroendocrine, neurobiological, and neurocognitive abnormalities implicated in emotion-processing deficits in neurotypical development and ASD, and the possible epigenetic pathway involving the interaction of genetic disposition and attachment. While existing research has linked both attachment disorganisation (Green and Goldwyn 2002; van Ijzendoorn et al. 1999), as well as organised insecure attachment styles with poorer emotional outcomes than secure attachment styles (Brumariu and Kerns 2010), the focus of this review will be primarily on the organised forms of attachment. 


\section{Autism Spectrum Disorders: The Contribution of Nature}

ASD are lifelong, neurodevelopmental disorders characterised by varying levels of social and communicative deficits, as well as the presence of restricted and repetitive patterns of behaviour and interests (APA 2013). Table 1 outlines diagnostic criteria for ASD as defined by the DSM-5 (APA 2013).

Although more research is warranted to clarify the role of epigenetic programming in ASD (Bale et al. 2010), it has been suggested that epigenetic programming in the pre, post, and peri-natal stages, for instance maternal psychosocial stress, can influence the onset and expression of ASD and its symptoms (Kinney et al. 2008; O’Connor et al. 2003). For instance, O'Connor et al. found that higher levels of maternal anxiety during pregnancy predicted more behavioural and emotional problems in 6,000 English children followed longitudinally from gestation to 7 years of age. This association held even after controlling for post-natal maternal anxiety, obstetric complications, and family psychosocial disadvantage. Furthermore, evidence exists for the possible development of idiopathic autism in utero (Bailey et al. 1998; Kemper and Bauman 1993) where abnormal cell numbers or congenital syndromes can alter neuroanatomy (Parisi et al. 2004). Subsequent aberrant apoptosis and synaptic pruning in the first few years of life have been found to relate to early neural overgrowth in children specifically between 2 and 4 years of age (Courchesne et al. 2007) in regions of the brain implicated in emotion processing; particularly, the frontal lobe, temporal lobe, and the limbic system (Carper et al. 2002; Hazlett et al. 2005). Decreased cerebellar volumes have consistently been found in young children with ASD (Webb et al. 2009; Sparks et al. 2002). Peri-natal factors have also emerged as potential environmental risk factors for ASD, in particular, fetal distress from obstetric complications such as emergency caesarean sections (Glasson et al. 2004), low birth weight (Hultman et al. 2002), and intrapartum hypoxia (Kolevzon et al. 2007). Conversely, other studies such as those of Bolton et al. (1997) suggest that obstetric complications do not constitute an environmentally mediated risk for ASD. Given that genetic heterogeneity is suspected in ASD (Piggot et al. 2009), together with a broad range of possible epigenetic contributions and behavioural manifestations across this disorder (Grossman et al. 2000), there is a need for a multi-dimensional approach to understanding the diverse factors underlying the onset and expression of ASD symptomatology.

In light of the emotion-processing deficits seen in ASD groups from as young as 1 year of age (Cassel et al. 2007; Toth et al. 2007), there is a gap in the literature relating to how attachment, an environmental factor, may interact with organic emotion-processing deficits to predict subsequent emotional difficulties in this group. The next section will review existing knowledge on attachment patterns in children with
Table 1 DSM-5 diagnostic criteria for 299.00 autism spectrum disorder

A. Persistent deficits in social communication and social interaction across multiple contexts, as manifested by the following, currently or by history (examples are illustrative and not exhaustive; see text):

1. Deficits in social-emotional reciprocity, ranging, for example, from abnormal social approach and failure of normal back-and-forth conversation, to reduced sharing of interests, emotions, or affect, and to failure to initiate or respond to social interactions

2. Deficits in nonverbal communicative behaviours used for social interaction, ranging, for example, from poorly integrated verbal and nonverbal communication, to abnormalities in eye contact and body language or deficits in understanding and use of gestures, and to a total lack of facial expressions and nonverbal communication

3. Deficits in developing, maintaining, and understanding relationships appropriate to developmental level, ranging, for example, from difficulties adjusting behaviour to suit various social contexts, to difficulties in sharing imaginative play or in making friends, and to absence of interest in peers

B. Restricted, repetitive patterns of behaviour, interests, or activities, as manifested by at least two of the following: currently or by history (examples are illustrative and not exhaustive; see text):

1. Stereotyped or repetitive motor movements, use of objects, or speech (e.g. simple motor stereotypes, lining up toys or flipping objects, echolalia, and idiosyncratic phrases)

2. Insistence on sameness, inflexible adherence to routines, or ritualised patterns of verbal or nonverbal behaviour (e.g. extreme distress at small changes, difficulties with transitions, rigid thinking patterns, greeting rituals, need to take same route, or eat same food everyday)

3. Highly restricted, fixated interests that are abnormal in intensity or focus (e.g. strong attachment to or preoccupation with unusual objects, excessively circumscribed or perseverative interests).

4. Hyper- or hyporeactivity to sensory input or unusual interest in sensory aspects of the environment (e.g. apparent indifference to pain/temperature, adverse response to specific sounds or textures, excessive smelling or touching of objects, and visual fascination with lights or movement)

C. Symptoms must be present in the early developmental period (but may not become fully manifest until social demands exceed limited capacities or may be masked by learned strategies in later life)

D. Symptoms cause clinically significant impairment in social, occupational, or other important areas of current functioning

E. These disturbances are not better explained by intellectual disability (intellectual developmental disorder) or global developmental delay. Intellectual disability and autism spectrum disorder frequently cooccur; to make comorbid diagnoses of autism spectrum disorder and intellectual disability, social communication should be below than what is expected for general developmental level.

ASD, in order to explore how the attachment relationship may interplay with the early neural events underlying the primary emotion-processing deficits seen in ASD.

\section{ASD and Attachment: What is Known?}

Attachment is commonly conceptualised as the biobehavioural relational system that infants develop with their 
primary caregiver, in most cases the mother, and is the result of the child's experiences in interaction with the caregiver across the first year of life (Ainsworth et al. 1978; Bowlby 1982). This relationship has been found to manifest in the form of attachment behaviours in situations where the child is distressed or tired, or when threats in the environment exist (Ainsworth et al. 1978; Bowlby 1982). Longitudinal studies such as that of Grossmann et al. (2005) suggest that children's developmental working models, pervasive mental representations, and schemas about the self, the other, and the relationship between the two, based on early attachment relationships with their primary caregiver, which influence behavioural, emotional, and psychological functioning throughout the lifespan (Shorey and Snyder 2006).

Attachment should be distinguished from emotional responsivity in that attachment is first developed as a relational system with the infant's primary caregiver, which then goes on to influence relationships with others through to adulthood. Emotional responsivity, on the other hand, does not stem solely from the relational system with the primary caregiver and involves the overall regulation of emotional responses to respond appropriately to socio-emotional displays of others (Konstantareas and Stewart 2006; Begeer et al. 2008), as well as the regulation of spontaneous emotional displays aimed at facilitating desired communicative goals (Bachevalier and Loveland 2006). Emotional responsivity is not necessarily first developed as a relational system or dyad.

Attachment classifications in infants and children between 12 and 21 months have been predominantly assessed using the strange situation procedure (SSP; Ainsworth et al. 1978), where the child is confronted with a stranger and two short separations from the caregiver in laboratory setting. Table 2 outlines the attachment styles which have been identified.
Studies have consistently found that attachment security can be adequately measured by modified versions of the SSP in young children with ASD (see Rutgers et al. (2004) for a review). It should be noted that the majority of studies on ASD and attachment have mainly been conducted in preschoolers as the diagnosis for ASD becomes increasingly valid with age (Charman and Baird 2002).

While some literature suggests that young children with ASD tend to react similarly to TD children to a separation from the parent with increased proximity-seeking behaviour (Bernabei et al. 1998; Sigman and Mundy 1989), others suggest that children with ASD display fewer responses and lower sensitivity to maternal approaches in general than matched TD children (Rutgers et al. 2007; van Ijzendoorn et al. 2007). Evidence has emerged suggesting that while children with ASD are able to form secure attachment relationships, secure attachments may be underrepresented in this group, and parent-child relationships may be characterised by less sensitivity, flexibility, and synchronous interaction than TD children, directly related to social impairments characteristic of ASD (Beurkens et al. 2013; Rutgers et al. 2004; Naber et al. 2007). A meta-analysis of 10 studies on attachment in children with ASD ( $N=287$; Rutgers et al. 2004) showed that children with ASD were significantly less securely attached to their parents than children with intellectual disability, language delays, and TD children (combined effect size across studies; Cohen's $d=0.50, r=0.24)$. Nevertheless, given that other studies have purported that school-aged children with ASD are as securely attached to their caregivers, particularly mothers, as are matched TD children (Bauminger et al. 2010; Chandler and Dissanayake 2013), knowledge on the prevalence of attachment security and the nature of attachment relationships in children with ASD is an area that warrants further consolidation.
Table 2 Attachment classifications and their descriptions (Ainsworth et al. 1978)

\begin{tabular}{cc}
\hline Attachment classification & Description \\
\hline Secure attachment (type B) & $\begin{array}{c}\text { Child strikes a balance between attachment and exploratory behaviour; uses } \\
\text { the caregiver as a base from which to explore. During separation, child } \\
\text { may show signs of distress. Upon reunion, child actively seeks contact } \\
\text { with caregiver, is easily settled, and returns to play. }\end{array}$ \\
$\begin{array}{c}\text { Insecure avoidant attachment } \\
\text { (type A) }\end{array}$ & $\begin{array}{c}\text { Continuous exploration is a strategy aimed at minimizing attachment } \\
\text { behaviour. Child shows little or no distress to the attachment figure leaving. } \\
\text { Upon reunion, child does not seek proximity or contact with caregiver, but } \\
\text { instead avoids them, looks away, or plays with toys. } \\
\text { (type C) } \\
\text { Child continuously seeks contact with caregiver at the expense of exploration. } \\
\text { During separation, child shows high levels of distress. Upon reunion, a mix } \\
\text { of contact resistance and seeking behaviours are combined, and the child is } \\
\text { difficult to settle. } \\
\text { Inability to develop a specific organised attachment pattern with their primary } \\
\text { caregiver. Child demonstrates contradictory behaviours upon separation and } \\
\text { attachment (type D) } \\
\text { reunion, including expressions of fear or apprehension regarding the parent, } \\
\text { stereotypes, undirected movements and expressions, and freezing or stilling } \\
\text { of all movement with a disoriented expression (Main and Solomon 1986). }\end{array}$ \\
\hline
\end{tabular}


One possible factor that has been suggested to account for the variability in findings across studies pertaining to the prevalence of secure attachments in ASD populations is that of cognitive ability (Willemsen-Swinkels et al. 2000; Capps et al. 1994). Children with ASD and comorbid intellectual disability have been found to be less securely attached than comparisons without intellectual disability (Yirmiya and Sigman 2001). Lower cognitive ability has also consistently been related to greater levels of attachment disorganization and lower levels of attachment security in young children with ASD (Naber et al. 2007; Willemsen-Swinkels et al. 2000). Further compounding this notion, the meta-analysis by Rutgers et al. (2004), as well as studies such as those of Bauminger et al. (2010) and Chandler and Dissanayake (2013), also indicated that in samples of children with highfunctioning ASD, levels of attachment security were comparable to comparison children who were similar in cognitive ability. Secondly, it has been suggested that the another factor influencing the inconsistency in findings of secure attachment behaviour in children with ASD that the majority of studies to date have measured attachment using the formal categorizations of the quality of attachment (Grzadzinski et al. 2014), which may consequently prevent the elucidation of distinct patterns of parent-child interactions unique to ASD beyond the formal categorizations (Rogers et al. 1993). Given that children with ASD have unique and distinctive characteristics, interests, family dynamics, and social interaction deficits from TD children (Phelps et al. 2009), there is a need for qualitative explorations of attachment behaviour in children with ASD (such as that of Grzadzinski et al. 2014) in order to further clarify patterns of attachment security in this population.

Furthermore, increased severity of ASD symptomatology and more strictly defined ASD diagnoses have been linked to lower levels of attachment security (Beurkens et al. 2013; Rutgers et al. 2004, 2007). Given the empirical notion that lower cognitive ability predicts increased severity of ASD symptoms such as social impairment (Joseph et al. 2002; Wing and Gould 1979) and also negatively correlates with the security of attachment in this group (Capps et al. 1994; see also van Ijzendoorn et al. 2007), the moderating influence of cognitive functioning on the relationship between attachment and ASD symptom-severity warrants future investigation.

Another reason purported for the finding that children with more strictly-defined ASD diagnoses demonstrate both lower levels of attachment security as well as less responsiveness to caregivers is that parents of children with more severe ASD symptomatology may be less able to establish a secure attachment relationship with their child because of the severity of the impairment in reciprocal social interaction of their child (Rutgers et al. 2007) and the resulting parenting stress and psychological problems related to having a child with ASD (Davis and Carter 2008). Compounding the notion that the formation of the attachment relationship is bi-directional and contingent on the characteristics and interactions of both the caregiver and the child (Jones and Schwartz 2009; DoussardRoosevelt et al. 2003), it has been found that the deficits in reciprocal social interaction and engagement that infants and children demonstrate in ASD (Adamson et al. 2001) influence the responses of caregivers, in that caregivers may adjust the nature of their interaction with the child in response to the child's behaviour (Doussard-Roosevelt et al. 2003). For instance, caregiver responsiveness and synchrony is not frequently reinforced due to the child's rejection of maternal social bids for interaction (Adamson et al. 2001).

Recent empirical literature has explored social and emotional development in infant siblings of children with ASD, commonly referred to as 'high-risk' infants (see reviews by Rogers 2009; Tager-Flusberg 2010). The literature has consistently showed that there is little differentiation in socioemotional engagement during the early months of life between genetically 'high-risk' infants who later develop ASD compared to those who do not develop ASD, as well as with controls who do not have a sibling with ASD ('lowrisk' infants), who also do not develop ASD (TagerFlusberg 2010; Ozonoff et al. 2010; Young et al. 2009). Nevertheless, by around 12 months, reduced smiling (Cassel et al. 2007; Toth et al. 2007), poorer social communication skills (Toth et al. 2007), reduced responding to bids for joint attention (Presmanes et al. 2007), as well as reduced responding to their own name (Nadig et al. 2007), aspects closely related to parent-child interactions, have been observed in genetically 'high-risk' infants compared to 'low-risk' infants. Moreover, by around 12 months, 'high-risk' infants later diagnosed with ASD have been observed to have poorer effortful emotion -regulation as well as lower responsiveness to reward cues when compared to high-risk infants who do not receive a subsequent diagnosis of ASD and low-risk controls (Garon et al. 2009). Moreover, individual differences in caregiver stress and coping styles have also been found to mediate the relationship between the early social disengagement demonstrated by a child with ASD and the responsiveness and synchrony demonstrated by the caregiver (Lyons et al. 2010). Although more research is needed to clarify and delineate the trajectory of social and emotion-processing deficits in infancy, it is apparent that interactions within the parentchild dyad by around the first year of life are clearly influenced by emerging socio-emotional deficits core to ASD. The following section reviews current empirical knowledge on the emotion-processing deficits seen in childhood in ASD, following which the neurobiological, neuroendocrine, and neurocognitive factors underpinning these deficits are discussed. The interactions of these factors with attachment factors are considered based on current empirical and theoretical notions. 


\section{Emotion Processing in ASD}

In light of the strong links that emotion-processing difficulties have with social, emotional, and behavioural maladjustment (Bauminger 2002) as well as with the increased risk of later psychopathology (Allen et al. 1996), current research has focused on delineating unique patterns of deficits and their underlying mechanisms in groups of children who have been found to possess difficulties in emotion processing (Rieffe et al. 2007; Smith and Walden 1999). Various integrative developmental models have provided useful ways in which to conceptualise the development of social-emotional-processing deficits in childhood in the context of their neural and biological underpinnings, for instance the Social Emotional Learning Framework (Lipton and Nowicki 2009) and the SOCIAL model (Beauchamp and Anderson 2010). Such models provide support for the notion that higher order social-emotional processes such as social judgement and social problemsolving, for which neural processes mature progressively through childhood and adolescence, are linked to the basic and distinct processes of emotional awareness, understanding, and regulation, which are seen earlier in development (Beauchamp and Anderson 2010). Existing research in children with ASD implicates overarching deficits in emotionregulation encompassing emotional reciprocity and expression (Konstantareas and Stewart 2006; Heerey et al. 2003), while there is less consensus on the nature of emotionrecognition deficits (Rump et al. 2009; also see review by Harms et al. 2010).

\section{Emotion Recognition}

Emotion recognition commonly encompasses the ability to identify, label, and be aware of the emotions of oneself and others (Heerey et al. 2003; Lipton and Nowicki 2009). In ASD populations, there has been a primary focus on facial emotion recognition (FER) of basic and complex emotions in the measurement of emotion recognition (Evers et al. 2014; Riby and Hancock 2008; Pelphrey et al. 2002; Behrmann et al. 2006). The majority of current findings postulate that both high and low-functioning children, adolescents, and adults with ASD are less accurate than TD groups in the recognition of complex emotions, such as embarrassment and trustworthiness, from non-verbal expressions (Adolphs 2001; Heerey et al. 2003; Dziobek et al. 2006). However, conflicting findings have arisen from such tasks when exploring basic emotion recognition, with some studies finding that normally-intelligent children and adults with ASD are impaired in the recognition of basic emotions (such as happiness and sadness; Kuusikko et al. 2009; Downs and Smith 2004), and others suggesting that ASD groups of varying levels of functioning are able to accurately recognise basic emotions at comparable levels to age and IQ-matched TD children and adults (Prior et al. 1990; Grossman et al. 2000).

A salient observation made by a review of FER in children and adults with ASD (Harms et al. 2010) was that despite inconsistencies in FER findings in behavioural studies, eyetracking, neuroimaging, and ERP studies more consistently suggest underlying deficits in the neural mechanisms underlying basic FER, indicating possible limits in the sensitivity of various behavioural measures to detect core FER deficits in ASD. Recent empirical studies employing both behavioural and neurological or electrophysiological measures to explore FER in children, adolescents, and adults with ASD have revealed systematic deficits in neural processes (Apicella et al. 2013; Wong et al. 2008), such as mental state decoding (Wong et al. 2008) and slower social information-processing speed (Lerner et al. 2013), underlying FER in young people with ASD, in the absence of deficits on behavioural FER measures (Lerner et al. 2013; Wong et al. 2008). Such studies suggest that firstly, there may indeed be heterogeneity within groups of individuals with ASD to recognise emotion. Secondly, these studies indicate that although individuals with ASD may have apparently intact emotion-recognition abilities as measured by controlled behavioural paradigms, there may be deficits in the ability to tap into the neural mechanisms underlying emotion processing which are seen as automatic processes in TD individuals. Accordingly, paradigms closely resembling naturalistic settings (Heerey et al. 2003; Rump et al. 2009) have often indicated deficits in emotion recognition in children with ASD.

Further, the measurement of emotion recognition often tends to be confounded by the differing demands of FER tasks, such as time limits or the nature of facial stimuli (Behrmann et al. 2006). Children, adolescents, and adults with ASD have been found to rely on more effortful and deliberate cognitive processing when engaging in emotion-recognition tasks than matched TD groups (Neumann et al. 2006; Lerner et al. 2011), and thus, emotion-recognition performance in this group is more vulnerable to task demands (Harms et al. 2010; Hill and Frith 2003). The review of FER studies in children and adults with ASD by Harms et al. (2010) suggests that individuals with ASD may employ compensatory mechanisms such as verbal mediation or feature-based learning to pass FER tasks.

A study by Evers et al. (2014), which incorporated hybrid faces comprising an emotional face-half (where the upper or lower face region demonstrated happiness, anger, sadness, or fear), with the other face-half showing a neutral expression, did not find an emotion-recognition deficit in children with high-functioning ASD. Nevertheless, findings from this study suggested that while both children with ASD and TD children similarly attended to mainly the eye and mouth areas when correctly recognising emotions, across ASD and TD groups, whether the child attended to the eye or mouth region was 
strongly emotion-dependent. This latter finding has implications for the comparison of emotion-processing performance in ASD groups across different paradigms, particularly that differences in the nature of facial stimuli and emotions presented across tasks may account for the variation in findings of emotion-recognition performance across ASD groups.

Recent studies have also suggested that the varying rates of emotion-recognition impairments seen across ASD may be accounted for by varying levels of co-occuring alexithymia in ASD populations, a sub-clinical condition in which an individual has impairments in identifying and describing their own emotional states (Cook et al. 2013; Bird and Cook 2013). Impairments in empathy, commonly described as the experience of another's emotional state stemming from an individual's perception of this emotional state, have also been linked to the occurrence of alexithymia in ASD populations (Bird et al. 2010). Given findings from behavioural studies of lower levels of affect-sharing, as well as fewer comforting behaviours and expressions of concern in children with ASD than TD groups in response to others' emotional expressions (Corona et al. 1998), as well as findings of impaired empathic accuracy (Demurie et al. 2011), future investigations are warranted to further investigate the alexithymia hypothesis in relation to the emotion-processing deficits seen in ASD. Furthermore, a current body of research exists indicating a negative relationship between security of attachment and alexithymia in TD groups (Fasihi et al. 2013; Wearden et al. 2003). Given that the majority of studies in this area have investigated TD populations, future studies are needed to delineate the interrelationships between alexithymia, emotion recognition, empathy, and attachment in ASD, a population with existing organic impairments in emotion recognition and empathy.

In TD children, preliminary evidence has emerged positively linking attachment security with facial emotionrecognition ability (Steele et al. 2008). However, future research exploring the link between attachment security and emotion recognition are needed in order to clarify this relationship in both ASD and TD groups, as well as to explore how attachment security interacts with others factors such as cognitive processes in predicting emotion-recognition ability.

\section{Emotion Regulation}

There is an increasing breadth of literature across the developmental trajectory on the neural underpinnings of emotionregulation, which is commonly conceptualised and measured as the ability to automatically or intentionally modify one's emotional state to facilitate goal-directed or adaptive behaviour (Samson et al. 2012; Waters et al. 2010). Emotion regulation is seen to be influenced by both intrinsic and extrinsic factors, where intrinsic factors refer to those which are seen to be internal or self-driven, for instance, temperament (Rothbart and Sheese 2007), physiological and neural systems involved in control processes (Fox 1994; Porges et al. 1996), and cognitive development (Fox et al. 1994). Extrinsic factors refer to external influences, and often refer to the role of bi-directional caregiver-child interactions, particularly the child's signalling of emotions, the interpretation and response to the child's signals of emotions, and consequently, scaffolding strategies for modulating emotional arousal (Sroufe 1996). With repeated early dyadic interactions where the caregiver attends to and employs a range of strategies to modulate the child's emotions (Feldman et al. 2004), together with the maturation of cognitive and attentional processes (Posner and Rothbart 2000), by early childhood, the child gradually moves to a relatively more independent regulation of emotion than in infancy or toddlerhood (Bowlby 1982; Bronson 2000). While more research is needed to consolidate the profile of emotion regulation across ASD, current studies suggest that children and adolescents with ASD are impaired in the use of emotion-regulation strategies, as measured by behavioural and biologically-based paradigms (see Mazefsky et al. 2013). Children with ASD have been found to respond impulsively to emotional stimuli with tantrums, aggression, or self-injury (Mazefsky et al. 2013; Sofronoff et al. 2007), as well as with lower anger and frustration tolerance (Jahromi et al. 2012; Ho et al. 2012).

Emotional Reciprocity Children with high and lowfunctioning ASD have been found to demonstrate socially inappropriate or unusual affect compared to TD children when responding to the emotions of others (Konstantareas and Stewart 2006; Joseph and Tager-Flusberg 1997; Bieberich and Morgan 1998). Nevertheless, behavioural and physiological studies exploring responsiveness to others' emotions have found that this is a complex ability that relies on social and cognitive skills that are highly confounded with age and cognitive ability (Begeer et al. 2008; Reddy et al. 2002). Whereas a concrete ability to manipulate and reciprocate the emotions of others is evident by toddlerhood and preschool in TD populations (Jackson and Tisak 2001), for instance, by showing comforting behaviours (Roth-Hanania et al. 2000), preschool children with ASD demonstrate an impaired ability to modify their emotions appropriately in response to others (Konstantareas and Stewart 2006; Corona et al. 1998). School-aged children with ASD respond to emotional expressions with less concern and comforting behaviour and tend to share affect less often with others (Corona et al. 1998). It has been suggested that there is a rather heterogeneous behavioural manifestation of deficits in the ability to regulate emotion in response to emotional stimuli, ranging from flattened affect in response to others' emotions (Loveland 2005) to demonstrating heightened expressions of emotions, albeit in inappropriate ways (Sofronoff et al. 2007; Mazefsky et al. 2013; Bauminger 2002; Reddy et al. 2002). 
Emotional Expression The expression of emotions has been found to be a vital aspect of emotion regulation as it signals the individual's internal states, consequently, facilitating sociocommunicative interaction (Bachevalier and Loveland 2006; Spinrad et al. 2004). The existence of a mental state lexicon has been found to drive emotional expressions in typicallydeveloping populations (Taumoepeau and Ruffman 2008) and ASD populations (Tager-Flusberg 1992; Happe 1993). By age three, TD children are able to regulate their own emotional states by expressing or suppressing their feelings according to the situation (Malatesta and Haviland 1982; Zeman et al. 2006), as well as to express complex emotions such as shame and pride (Saarni 1999). Children with ASD have been found to lack appropriate and spontaneous expressions of emotion, as mediated by a lack of mental state language (TagerFlusberg 1992; Happe 1993).

Current knowledge on the verbal and non-verbal emotionexpression ability of young children with ASD suggests that prior to preschool age, some children with ASD show similar abilities in affective expressiveness as TD children (Baranek 1999; Palomo et al. 2006). However, there is a critical need for more studies of emotional expression in this age group in order to conclusively identify specific and subtle impairments which may exist. Nevertheless, some behavioural measures of emotional expression in ASD groups beyond preschool, into adolescence and adulthood, propose a pattern of flat, neutral, or idiosyncratic expressions (Czapinski and Bryson 2003; Hobson and Lee 1998) compared to controls matched for mental age. Some of the literature suggests that particularly children and adolescents with high-functioning ASD are able to verbally express emotions (Jaedicke et al. 1994) and give examples of feeling states from their own experience (Yirmiya et al. 1992) at comparable levels to those of TD groups. Conversely, other studies have found that these groups lack selfawareness of their emotions (Tager-Flusberg 1992; Happe 1993; Yirmiya et al. 1989) and are less able than TD controls to generate emotionally charged situations from their own experience (Rieffe et al. 2007).

A possible factor accounting for the inconsistency in findings relates to the lack of uniformity of behavioural paradigms used to measure this aspect of emotion-regulation. Specifically, it has been suggested that data obtained under laboratory conditions as opposed to naturalistic settings may present an overly positive perspective on emotion-expression skills of children with high-functioning ASD (Begeer et al. 2008). Consequently, it is vital for future paradigms to replicate participants' socio-emotional environment as much as possible to ensure the accurate measurement of emotional expression. Although knowledge of the relationship between insecure attachment and the ability to verbally discuss and express emotion in ASD is still in its infancy, there is a strong evidence in TD populations that secure attachment relationships predict the child's subsequent internal state language (Meins et al.
2001; Fonagy et al. 1991). In order to conclusively attribute unique patterns of affective expression to ASD populations, future research should examine the role of internal state language and early mother-child relationships across ASD groups within the same paradigms and methodology.

\section{Theory of Mind}

In TD children, maternal responsiveness to the emotional displays of infants have been found to positively predict the child's subsequent ability to understand and respond appropriately to emotional displays by others (Steelman et al. 2002; Zeanah et al. 2002). While it has also been suggested that the quality and frequency of caregiver-infant interactions in the early years of life influence the development of reflective functioning (Fonagy and Target 1997; Slaughter et al. 2007) and a theory of mind (ToM), or mentalization (Meins et al. 2001; Ruffman et al. 2002), in ASD groups, the relative contributions of levels of organic ASD symptomatology and attachment to ToM ability have not been compared and clarified in this group.

Impairments in ToM have been found in children with ASD (Heerey et al. 2003; Dziobek et al. 2006), which affect not only the understanding of and responses to others' mental and emotional states (Dodge et al. 1995), but have also been found to extend to deficits in their awareness of the child's own mental states, as evidenced by existing findings of a lack of mental state language (Raikes and Thompson 2006; TagerFlusberg 1992; Happe 1993) and inappropriate expression of emotion in both groups of children (Shields et al. 1994; Sigman et al. 1992).

While findings of ToM impairments in high-functioning ASD groups are relatively inconsistent in structured test settings (Happe 1995; Bauminger 2002), clear impairments are revealed in naturalistic test settings (Rump et al. 2009; Dziobek et al. 2006) and in everyday functioning (Rieffe et al. 2000), suggesting that paradigms which measure ToM in environments that are not representative of real-world social settings may not provide an accurate pattern of ToM functioning in ASD groups (Adolphs 2001; Baron-Cohen et al. 1985; Klin 2000; Leslie and Frith 1990; Weeks and Hobson 1987). Nevertheless, impairments in the understanding of others' beliefs, intentions, and emotions have been found to positively influence accurate emotion recognition, reciprocity, and expressiveness in ASD populations (Heerey et al. 2003; Sigman et al. 1992; Loveland 2005; Bauminger 2002). Positive relationships have been found between ToM ability and empathy in children and adults with ASD (Rogers et al. 2007; Yirmiya et al. 1989). There is also emerging evidence for a hostile attributional bias in ASD, stemming from the inability to accurately perceive the mental and emotional states of others (Whitehouse et al. 2009; Meyer et al. 2006; Loveland et al. 2001). 


\section{Internalizing and Externalizing Difficulties in ASD}

In addition to exploring emotion-regulation capacity in children with ASD, recent research has increasingly focused on delineating the profile of emotional and behavioural difficulties in children with ASD which have been purported to be related to emotion-regulation capacity (Matson and NebelSchwalm 2007; Roskam et al. 2011; Simonoff et al. 2008). The distinction between internalizing and externalizing symptomatology is commonly used as a framework for conceptualising emotional and behavioural difficulties in both clinical and non-clinical populations (Achenbach and Edelbrock 1979). Internalizing difficulties refer to innerdirected symptoms of disordered mood or emotion (Brumariu and Kerns 2010; Kovacs and Devlin 1998); including somatic complaints, anxiety, depression, and social withdrawal. Externalizing difficulties consist of negative behaviours directed at others or the environment; commonly seen as aggression and disruptive, rule-breaking behaviours (Achenbach and Edelbrock 1979; Laghi et al. 2013).

In studies of TD children, higher attachment security has been linked to lower levels of internalizing (Dallaire and Weinraub 2007; Dubois-Comtois et al. 2013) and externalizing (Fearon et al. 2010; Fearon and Belsky 2011) symptomatology. The child's internal representations of their caregiver's availability and responsiveness are seen to influence how they signal and modulate distress in the context of their attachment relationship, and consequently, influence the development of subsequent internalizing and externalizing symptomatology (Dubois-Comtois et al. 2013; Brumariu and Kerns 2010). Both forms of organised insecure attachment, namely, avoidance (Munson et al. 2001; Fearon and Belsky 2011) and ambivalence (Dubois-Comtois et al. 2013; Moss et al. 2006), have been proposed to be risk factors for higher levels of externalizing behaviour, for instance, aggressive and rule-breaking behaviour, conduct problems, and impulsive/hyperactive behaviour. Similarly, both attachment avoidance (Groh et al. 2012) and attachment ambivalence (Colonnesi et al. 2011; Brumariu and Kerns 2010) have been purported to be risk factors for higher levels of internalizing symptomatology. To date, only one study (Bauminger et al. 2010) has explored the relationship between attachment security and internalizing and externalizing difficulties in children with ASD in the middle childhood period. While this study did not find a relationship between attachment security and internalizing and externalizing difficulties, given the dearth of research exploring this link, further studies will be invaluable in clarifying the influence of attachment security on subsequent emotional and behavioural outcomes in ASD.

Some studies suggest that cognitive ability influences levels of internalizing and externalizing difficulties in children with ASD (Witwer and Lecavalier 2010; Maskey et al. 2013), and subsequently, influences group differences on these outcomes compared to TD groups. Conversely, others claim that cognitive ability is unrelated to levels of externalizing and internalizing symptomatology (Simonoff et al. 2008). Nevertheless, in studies of ASD and TD children and adolescents without intellectual disability where groups are similar on cognitive ability, there is consistent evidence for higher rates of internalizing difficulties, particularly anxiety (Strang et al. 2012) and depressive symptoms (Mazzone et al. 2013; Meyer et al. 2006), as well as externalizing symptomatology, in particular aggression, conduct problems, and oppositional behaviour across childhood and adolescence in ASD than TD groups (Bauminger et al. 2010; also see review by Mazzone et al. 2012). Studies of children and adolescents with ASD across a range of cognitive abilities have also suggested that ASD symptom severity may be related to the severity of anxiety and depressive symptomatology (Kanne et al. 2009; Mazzone et al. 2012), as well as to externalizing symptomatology, particularly problem behaviours (Matson et al. 2008).

The current literature indicates relatively higher levels of comorbid internalizing and externalizing symptomatology in ASD groups than in TD populations. Moreover, empirical studies suggest that attachment insecurity may be a risk factor for comorbid emotional and behavioural difficulties. As indicated in the past studies, the severity of core socio-emotional impairments seen in ASD correlate positively with levels of comorbid internalizing and externalizing difficulties. Given the link between attachment insecurity and internalizing and externalizing disorders seen in TD literature, future studies should investigate whether attachment difficulties may interact with these core socio-emotional impairments to further compound the levels of comorbidity in ASD groups, accounting for higher levels of internalizing and externalizing difficulties in ASD groups compared to TD groups. Future research should also explore the dynamics of the interaction between core ASD deficits and attachment orientations in predicting comorbidity of emotional or behavioural disorders in children with ASD. The next section explores the role of neurobiological and neurocognitive factors in the development of emotion-processing ability.

\section{Neuroendocrine, Neurobiological, and Neurocognitive Factors in Emotion Processing}

There has been much recent support and strong empirical evidence for the notion that early environmental experiences, particularly in the first 2 years of life, directly impact brain development (Schore 2000; Gunnar and Fisher 2006) through the elimination of un-used synaptic connections and the further development of others (Nelson and Bloom 1997). Accordingly, much preliminary evidence has arisen in recent years for the neurological basis of emotion-regulation and emotion recognition, where attachment interactions are seen 
as influencing the maturation of right-hemisphere neural structures involved in emotion processing (Frey and Petrides 2000; Schore 2009), as well as the autonomic nervous system which manifests the somatic aspects of emotion, such as crying (Porges et al. 1994). It has been suggested that in typical development, bidirectional caregiver-child interactions within the attachment relationship may influence neurovulnerability to difficulties in stress and emotional regulation (Schore 2002, 2009; Allen et al. 1996).

\section{Neuroendocrine Systems and Emotion Regulation}

Research into the role of the hypothalamus-pituary-adrenal (HPA) axis and limbic regions in emotion regulation has been receiving increased interest in ASD (Corbett et al. 2006; Richdale and Prior 1992) and TD populations (Hatzinger et al. 2007) given its established role as a major stress response system (McCrory et al. 2010). Emotion-regulation ability across childhood and adulthood has been found to be largely dependent on the experience-dependent regulation of the HPA axis developed within the first year of life (Schore 2009; Gunnar and Quevedo 2007). In a typical development, infants are able to use their parents to help regulate their emotions, specifically to respond appropriately to their emotional expressions and return them to a tolerable or positive emotional state (Bowlby 1982). The literature has implicated both child attachment security and parental sensitivity/responsiveness in the facilitation of HPA regulation in response to stressors (Roque et al. 2012; Ahnert et al. 2004). Specifically, the lower levels of attachment security and parental sensitivity have been linked to elevated cortisol levels in response to stressors (Bugental et al. 2003; Gunnar et al. 1992; Ahnert et al. 2004; Dozier et al. 2008).

TD infants from as young as around 10 months of age begin to find emotional meaning in their caregivers' faces and voices, and engage in social referencing with their caregiver to guide their behaviour and emotional reactions (Widen and Russell 2008). Given findings that children with ASD may demonstrate early core socio-emotional impairments from infancy (Yirmiya et al. 1989; Adamson et al. 2001), for instance, difficulties communicating their emotional states clearly (Yirmiya et al. 1989) and lower responsiveness to maternal interaction (Adamson et al. 2001), it is likely that these impairments may disrupt aspects of communication within the bi-directional attachment relationship from the first year of life. Early attachment disruptions have been found to act as a stressor, triggering the release of corticotrophin-releasing hormone and arginine vasopressin from the paraventricular nucleus of the hypothalamus, which stimulates secretion of adreno-cortico-trophic hormone (ACTH) at the anterior pituary (Federenko et al. 2004). This then acts on the adrenal cortex to synthesise and releases glucocorticoid hormones such as cortisol, enabling the mobilisation of stored glucose and lipid stores and contributing to various physiological changes aimed at prepare an individual to meet the energy demands associated with a stressful event, such as heightened vigilance to threat and readiness to use defensive responses (McCrory et al. 2010). Cortisol follows a circadian rhythm, a diurnal pattern which is well established by around 3 months of age (Price et al. 1983). It has been suggested that after prolonged and unpredictable attachments with caregivers in infancy, cortisol levels may be depleted and the feedback loops controlling hormone levels in the brain become dysregulated (Burke et al. 2005), resulting in the individual becoming highly sensitive to stress (Kaufman and Charney 2001). High levels of stress sensitivity, as commonly measured by elevated cortisol levels, has been consistently linked to higher risk of consequent internalizing and externalizing difficulties into adolescence (Shirtcliff and Essex 2008; Hastings et al. 2011). Some evidence has also emerged that low levels of cortisol may also increase risk for internalizing and externalizing difficulties (Shirtcliff et al. 2005; Gunnar and Vazquez 2001).

Studies exploring basal and simulated levels of cortisol, ACTH and circadian rhythms in children with ASD have not suggested a consistent profile of HPA axis responsivity across this diagnostic group (Levine et al. 2012; Schupp et al. 2013; Corbett et al. 2008; Richdale and Prior 1992), but nevertheless indicate a generalised sensitivity to both emotional and non-emotional stressors, rather than a specific stress response to social and emotional stimuli (Corbett et al. 2006; Levine et al. 2012; Richdale and Prior 1992). Some studies have found comparable basal salivary circadian rhythms and cortisol levels with TD children (Marinovic-Curin et al. 2008) while others propose conflicting findings of either higher (Richdale and Prior 1992) or lower (Curin et al. 2003) basal cortisol levels in ASD groups. In light of findings that children with ASD may have higher variability in stress responsivity and elevations in cortisol following exposure to a novel stimuli than TD children (see Corbett et al. 2006, 2008), there is a need to explore the environmental and biological factors that are likely to influence the responsivity of the HPA axis across ASD.

There is existing evidence that the sensitivity of the HPA axis in children with ASD is likely to be influenced by age (Corbett et al. 2010; Zinke et al. 2010) and early-emerging biologically-based or psychological factors such as sensory sensitivity (Corbett et al. 2009), as well as behavioural inhibition and temperament, which tend to be stable over time (Degnan and Fox 2007; Tyrka et al. 2006; Fox et al. 2008; Gunnar et al. 2003). Moreover, there is a consequent suggestion that children with ASD may be more responsive to environmental cues which can influence biological rhythms than are TD children (Corbett et al. 2006, 2008). Although this suggestion requires further empirical consolidation, further supporting this notion is the theory of differential 
susceptibility, which suggests that children, due to variation in temperament and genetics, differ in their responsivity, and consequently, susceptibility to both the beneficial effects of nurturing and desirable environments and the negative effects of adverse early environments (Belsky 2005; Belsky and Pluess 2009). Given that infants later diagnosed with ASD go on to develop varying levels of severity of emotion regulation deficits, there is much to be explored about moderating effect of biological sensitivity or reactivity of the individual child on the differential effects of early parent-child interaction experiences.

In summary, although a clear directional pattern of HPA axis dysregulation has not yet been delineated, it is suspected that ASD groups may demonstrate HPA axis dysregulation in response to discrete stressful situations, both social and nonsocial (Marinovic-Curin et al. 2008; Corbett et al. 2006). Moreover, the profile of HPA axis dysregulation across this diagnostic group appears varied; with biological, environmental, and psychological factors differentially influencing the early development of this system. Given the strong empirical findings that attachment interactions from infancy shape regulation of the HPA axis and consequently later stress and emotion-regulation, together with the notion that the nature of the child-caregiver relationship can differ across ASD groups (Lyons et al. 2010), the relationship between parentchild interactions and HPA axis regulation should be further clarified and consolidated by psycho-biological, observational and parent-report studies of infants identified as being at risk of being diagnosed with ASD.

\section{Neurobiological Evidence from Imaging Studies: Neural Structural and Functional Abnormalities Implicated in Emotion Processing}

PET, fMRI, and EEG investigations have implicated the hypoactivation of the medial prefrontal cortex/paracingulate cortex, temporal pole, tempero-parietal junction, amygdala, and periamygdaloid cortices in impaired emotion recognition and regulation in ASD populations of children and adults (Di Martino et al. 2009; Piggot et al. 2004; Dawson 2008). The meta-analysis by Di Martino et al. (2009) found that emotionrecognition impairments in ASD have been implicated particularly in the hypoactivation of the amygdala and fusiform 'face' area (FA) in the temporal lobe. Many other studies have also suggested that irregular and inconsistent patterns of fusiform gyrus activation, particularly, the right fusiform gyrus, has been implicated in impaired face processing in individuals with ASD (Dalton et al. 2005; Piggot et al. 2004; Pierce et al. 2001). Although abnormalities in emotion processing, in particular emotion regulation and expression, become evident in first 1 to 2 years of life (Zwaigenbaum et al. 2005), the majority of ASD studies have predominantly focused on studying brain structure of individuals more than 10 to 20 years after the onset of the disorder (Courchesne et al. 2007). Nevertheless, there is an increasing breadth of research shedding light on early neural abnormalities underlying later emotion processing in ASD (e.g. Webb et al. 2006; Dawson et al. 2002, 2004; Dawson 2008).

Existing MRI and retrospective head circumference studies have implicated early excesses in neuron numbers and brain overgrowth particularly during 2 to 4 years of age in specific regions of the brain; particularly, the frontal lobe, temporal lobe, and the amygdala (Carper et al. 2002; Hazlett et al. 2005). There is currently evidence of abnormal increases short-distance connectivity within these brain regions, but a lack of connectivity between regions mediating the integration and processing of social and emotional information (Kleinhans et al. 2008; Courchesne et al. 2007). Studies exploring neural connectivity via event-related potentials (ERP) to faces and facial expressions (Dawson et al. 2002; Webb et al. 2006; McPartland et al. 2004) suggest that children and adults with ASD show atypical and delayed eventrelated brain potentials to faces and facial expressions. For instance, Dawson et al. (2002) found that the differential neural activation seen in TD and mental-aged matched children with developmental delay when viewing their mother's face versus an unfamiliar face was not seen in 3 and 4-year-olds with ASD. Furthermore, children with ASD have been found to demonstrate atypical neural differentiation to a face expressing fear than a neutral face compared to TD children (Dawson et al. 2004). An impairment in the connectivity in the amydala-orbitofrontal circuit (Bachevalier and Loveland 2006), in particular, has been implicated in emotion-regulation and expression impairments in toddlers and young children with ASD (Carper et al. 2002). Reduced overall corpus callosum volumes have also been found in children and adults with ASD (Boger-Megiddo et al. 2006), further implicating deficits in long-distance neural connectivity and integration as contributing factors to emotion-processing deficits in ASD.

In summary, although imaging studies have not yet conclusively elucidated the structural and functional correlates of emotion processing in ASD groups, the current literature indicates reduced corpus-callosum volumes, decreased cerebellar volumes, and impaired connectivity between the orbitofrontal-limbic networks, shedding light on the possibility of deficits in long-distance neural connectivity and integration as contributing factors to emotion-processing deficits in ASD. The emerging notion that the bidirectional attachment relationship interacts differentially with the child's neurobiological systems to predict the development of ASD symptomatology, including emotionprocessing ability (Dawson 2008; Schore 2002, 2009), needs to be further consolidated through empirical studies incorporating neurological, biological, and physiological measures. The next session summarises current knowledge on Executive Functioning (EF) in ASD populations, a 
neurocognitive faculty which has been purported to underlie emotion-processing deficits in this group (Vollm et al. 2006).

\section{Neurocognitive Processes in Emotion Processing}

The literature largely conceptualises EF as a higher order cognitive function encompassing a set of goal-directed processes; namely inhibitory control, working memory, planning, set shifting, and cognitive flexibility (Hill 2004; Miyake et al. 2000). In both TD and ASD groups, EF ability has been linked to the ability to self-regulate emotions (Bridgett et al. 2012; Zelazo and Cunningham 2007). EF ability, for instance, the ability to attend to and shift from one frame of reference to another (Lee and Hoaken 2007), has also been seen to facilitate the understanding of others' emotional states (Carlson et al. 2004a), and has been found to predict social-emotional competence in TD (McKown et al. 2009) and ASD groups (Gilotty et al. 2002; Vollm et al. 2006). Generalised deficits in joint and reflexive attention and attention shifting have been implicated in the impairments ASD children and adults face with accurate facial emotion recognition (Mundy et al. 2009), although others suggest that facial emotion-recognition impairments are not characterised by such attentional deficits in gaze and face perception (Ames and Jarrold 2007), but rather by specific impairments in socio-emotional cognitive processes (Piggot et al. 2004).

Consistent deficits in planning and attentional flexibility have been found in children with ASD (Pellicano et al. 2006; Pennington and Ozonoff 1996; Winsler et al. 2007; Morgan et al. 2003), whereas paradigms assessing inhibition and working memory do not consistently reveal impairments (Goldberg et al. 2005; Hill 2004). EF deficits have been attributed to low degrees of integration of information across cortical areas resulting from reduced intracortical connectivity (Just et al. 2007), particularly the frontal lobe as well as cortico-cortical and cortico-striatal loops (D'Esposito 2007).

Studies of preschool and school-aged TD and ASD groups have drawn positive links between the EF faculty of inhibition and ToM ability (Joseph and Tager-Flusberg 2004; Carlson et al. 2004b), independent of age or cognitive ability. In both TD children and children with ASD, working memory, specifically the ability to hold information in mind while processing this information, has been found to positively relate to the ability to attribute mental states to one's self or others (Gordon and Olson 1998; Keenan et al. 1998; Joseph and TagerFlusberg 2004).

While the relationship between EF ability and facial emotion recognition (FER) requires further exploration, some preliminary evidence currently exists for a positive relationship between EF and performance on FER tasks in both preschool age (Rosenquist et al. 2014) and in middle childhood (Mathersul et al. 2009) in TD children.

\section{Summary and Future Directions}

Current research in children with ASD implicates overarching deficits in emotion regulation, encompassing emotional reciprocity and expression, while there is less agreement on the existence of emotion-recognition deficits across highfunctioning ASD groups. Nevertheless, existing studies suggest that cognitive ability may influence the levels of deficit experienced, and thus future studies exploring emotion processing in ASD should identify and control for group and individual differences in cognitive ability.

Neurological and electro-physiological studies indicate deficits in automatic processes underlying emotion recognition, despite behavioural findings not consistently findings deficits in emotion recognition. The literature indicates an emerging link between security of attachment and the ability to understand the emotional states of the self and others, as well as with adequate reciprocity towards the expression of emotional stimuli in ASD populations. In groups of TD children, positive links have also been drawn between attachment security and the child's ability to regulate emotional states. The high rates of internalizing and externalizing difficulties seen in children with ASD compared to matched TD groups, together findings that attachment insecurity acts as a risk factor for these difficulties, highlight the need for future studies investigating the influence of attachment insecurity on emotional and behavioural difficulties in children with ASD alongside organic explanations for emotion-processing deficits in this group.

Although the role that attachment influences play in emotion-processing difficulties in ASD groups is a relatively unexplored area, it is, however, known that the formation of parent-child attachment is bi-directional, specifically, that it is dependent on the characteristics of both the parent and the child or infant. Specifically, the development of attachment security in ASD appears to be dependent on a wide range of factors such as parent-child synchrony as mediated by the severity of the child's ASD symptomology, the child's cognitive ability, as well as parental stress and coping styles. Given that there has been a reliance on formal measures of attachment categorisations, there is a need to qualitatively explore the factors which mediate the bi-directional attachment relationship and how it interacts with the child's neural pathways to influence emotion-processing ability. Such explorations of attachment behaviours in children with ASD will help to further clarify the nature of secure attachment in this population while taking into account the characteristics, deficits, interests and family dynamics unique to ASD. Moreover, given the relative focus of attachment in infancy, toddlerhood, and early childhood in the ASD literature to date, future studies exploring the characteristics of attachment in older children and adolescents will be invaluable in contributing to knowledge on attachment relationships across the developmental trajectory in ASD. 
The empirical literature has consistently supported the role of genetic and epigenetic programming in the pre, post, and peri-natal stages in contributing to early structural neural abnormalities such as brain overgrowth in the first 2 to 4 years of life, decreased corpus callosum volumes and neuronal excesses, as well as the hypoactivation and abnormal patterns of connectivity between cortical and subcortical structures, namely, the frontal, temporal, and subcortical limbic networks, in particular, the orbitofrontal circuit in contributing to impairments such as emotion-processing difficulties in ASD. Preliminary evidence has arisen in recent years for the neurobiological basis of emotion dysregulation, where attachment interactions are seen as influencing the maturation of right-hemisphere structures involved in emotion processing and regulation. Nevertheless, there is emerging evidence of an interplay between parent-child interactions and structural neural alterations in the early months and years of life, which may influence the consequent trajectory of neuroendocrine, neurobiological and neurocognitive processes which have been found to play a role in emotion recognition and regulation. Consequently, there is a need to elucidate the underlying neural mechanisms by which early attachment influences emotion recognition, understanding, and regulation in ASD populations.

Evidence for the role of the HPA axis in emotion-regulation in children with ASD suggests that despite findings of abnormal HPA feedback-loop patterns, a clear directional pattern of HPA axis dysregulation has not yet been delineated, although it is suspected that ASD groups may demonstrate HPA axis dysregulation in response to discrete stressful situations, both social and non-social. Moreover, given the different levels of severity observed in emotion-processing deficits across populations of ASD children, the role of biological sensitivity and reactivity to environmental stressors in infancy and early childhood requires further exploration, particularly given that the socio-emotional deficits core to ASD are likely to influence the nature of attachment interactions from infancy.

Furthermore, given that deficits in the neurocognitive domain of executive functioning have also been postulated as influencing the emotion-recognition and regulation deficits seen in ASD and TD populations, future studies exploring the role of EF faculties alongside the role of attachment security on subsequent emotion processing in children with ASD will help to clarify the relative influences of attachment security and $\mathrm{EF}$ on the emotion-processing deficits seen in ASD.

\section{Conclusion}

The recent increased awareness of ASD and its subsequent increased prevalence (Liu et al. 2010) drives a greater urgency for research into all possible underlying contributors to the deficits seen in this disorder. Furthermore, this trend shows promise for a greater level of holistic empirical research in distinguishing the unique trajectory of emotion-processing deficits of ASD. The current literature suggests that emotion-processing deficits seen in ASD are likely influenced by a wide range of factors, including (a) early structural brain development in-utero, in infancy, and into childhood; (b) executive-functioning ability; (c) neuroendocrine processes such as dysregulation of the HPA axis; and (d) attachment relationships. Future studies exploring the influence of caregiver-child attachment relationships on established organic explanations for emotion-processing deficits seen in ASD will add to the existing substantial knowledge base about the impact of attachment relationships on neurobiological, neuroendocrine, and neurocognitive processes underlying the ability to process emotion.

\section{References}

Achenbach, T. M., \& Edelbrock, C. S. (1979). The child behavior profile: II. Boys aged 12-16 and girls aged 6-11 and 12-16. Journal of Consulting and Clinical Psychology, 47, 223-23. doi:10.1037/ 0022-006X.47.2.223.

Adamson, L. B., McArthur, D., Markov, Y., Dunbar, B., \& Bakeman, R. (2001). Autism and joint attention: young children's responses to maternal bids. Journal of Applied Developmental Psychology, 22, 439-453. doi:10.1016/S0193-3973(01)00089-2.

Adolphs, R. (2001). The neurobiology of social cognition. Current Opinion in Neurobiology, 11, 231-239. doi:10.1111/1467-9280. 00226.

Ahnert, L., Gunnar, M. R., Lamb, M. E., \& Barthel, M. (2004). Transition to child care: associations with infant-mother attachment, infant negative emotion, and cortisol elevations. Child Development, 75, 639650. doi:10.1111/j.1467-8624.2004.00698.x.

Ainsworth, M. S., Blehar, M. S., Waters, E., \& Wall, S. (1978). Patterns of attachment: a psychological study of the strange situation. Hillsdale: Erlbaum.

Allen, J. P., Hauser, S. T., \& Borman-Spurrell, E. (1996). Attachment theory as a framework for understanding sequelae of severe adolescent psychopathology: an 11-year follow-up study. Journal of Consulting and Clinical Psychology, 64, 254-263. doi:10.1037// 0022-006X.64.2.254.

American Psychiatric Association. (2013). Diagnostic and statistical manual of mental disorders (5th ed.). Washington: Author.

Ames, C. S., \& Jarrold, C. (2007). The problem with using eye-gaze to infer desire: a deficit of cue inference in children with autism spectrum disorder? Journal of Autism and Developmental Disorders, 37 , 1761-1775. doi:10.1007/s10803-006-0309-5.

Apicella, F., Sicca, F., Federico, R. R., Campatelli, G., \& Muratori, F. (2013). Fusiform gyrus responses to neutral and emotional faces in children with autism spectrum disorders: a high density ERP study. Behavioural Brain Research, 251, 155-162. doi:10.1016/j.bbr. 2012.10.040

Bachevalier, J., \& Loveland, K. A. (2006). The orbitofrontal-amygdala circuit and self-regulation of social-emotional behavior in autism. Neuroscience and Biobehavioural Reviews, 30, 97-117. doi:10. 1016/j.neubiorev.2005.07.002.

Bailey, A., Luthert, P., Dean, A., Harding, B., Janota, I., Montgomery, M., et al. (1998). A clinicopathological study of autism. Brain: A 
Journal of Neurology, 121, 889-905. doi:10.1093/brain/121.5. 889.

Bale, T. L., Baram, T. Z., Brown, A. S., Goldstein, J. M., Insel, T. R., McCarthy, M. M., \& Nestler, E. J. (2010). Early life programming and neurodevelopmental disorders. Biological Psychiatry, 68, 314 319. doi:10.1016/j.biopsych.2010.05.028.

Baranek, G. T. (1999). Autism during infancy: a retrospective video analysis of sensory-motor and social behaviors at 9-12 months of age. Journal of Autism and Developmental Disorders, 29, 213-224. doi: 10.1023/A:1023080005650.

Baron-Cohen, S., Leslie, A. M., \& Frith, U. (1985). Does the autistic child have a "theory of mind"? Cognition, 21, 37-46. doi:10.1016/00100277(85)90022-8.

Bauminger, N. (2002). The facilitation of social-emotional understanding and social interaction in high-functioning children with autism: intervention outcomes. Journal of Autism and Developmental Disorders, 32, 283-298. doi:10.1023/A:1016378718278.

Bauminger, N., Solomon, M., \& Rogers, S. J. (2010). Externalizing and internalizing behaviours in ASD. Autism Research, 3, 101-112. doi: 10.1002/aur.131.

Beauchamp, M. H., \& Anderson, V. (2010). SOCIAL: an integrative framework for the development of social skills. Psychological Bulletin, 136(1), 39-64. doi:10.1037/a0017768.

Begeer, S., Banerjee, R., Lunenburg, P., Meerum Terwogt, M., Stegge, H., \& Rieffe, C. (2008). Brief report: self-presentation of children with autism spectrum disorders. Journal of Autism and Developmental Disorders, 38, 1187-1191. doi:10.1007/s10803007-0503-0.

Behrmann, M., Thomas, C., \& Humphreys, K. (2006). Seeing it differently: visual processing in autism. Trends in Cognitive Sciences, 10, 258-264. doi:10.1007/s10803-014-2276-6.

Belsky, J. (2005). Differential susceptibility to rearing influence: An evolutionary hypothesis and some evidence. In B. J. Ellis (Ed.), Origins of the social mind: evolutionary psychology and child development. NY: Guilford Press.

Belsky, J., \& Pluess, M. (2009). Beyond diathesis stress: differential susceptibility to environmental influences. Psychological Bulletin, 135, 885-908. doi:10.1037/a0017376.

Bernabei, P., Camaigni, L., \& Levi, G. (1998). An evaluation of early development in children with autism and pervasive developmental disorders from home movies: preliminary findings. Autism, 2, 243258. doi:10.1177/1362361398023003.

Bettelheim, B. (1967). The empty fortress. Chicago: Free Press.

Beurkens, N. M., Hobson, J. A., \& Hobson, R. P. (2013). Autism severity and qualities of parent-child relations. Journal of Autism and Developmental Disorders, 43, 168-178. doi:10.1007/s10803-0121562-4.

Bieberich, A. A., \& Morgan, S. B. (1998). Brief report: affective expression in children with autism or Down syndrome. Journal of Autism and Developmental Disorders, 28, 333-338. doi:10.1023/ A: 1026016804357

Bird, G., \& Cook, R. (2013). Mixed emotions: the contribution of alexithymia to the emotional symptoms of autism. Translational Psychiatry, 3, 1-8. doi:10.1038/tp.2013.61.

Bird, G., Silani, G., Brindley, R., White, S., Frith, U., \& Singer, T. (2010). Empathic brain responses in insula are modulated by levels of alexithymia but not autism. Brain, 133, 1515-1525. doi:10.1093/ brain/awq060.

Bishop, D. V., Maybery, M., Maley, A., Wong, D., Hill, W., \& Hallmayer, J. (2004). Using self-report to identify the broad phenotype in parents of children with autistic spectrum disorders: a study using the autism-spectrum quotient. Journal of Child Psychology and Psychiatry, and Allied Disciplines, 45, 1431-1436. doi:10.1111/j. 1469-7610.2004.00325.x.

Boger-Megiddo, I., Shaw, D. W., Friedman, S. D., Sparks, B. F., Artru, A. A., Giedd, J. N., et al. (2006). Corpus callosum morphometrics in young children with autism spectrum disorder. Journal of Autism and Developmental Disorders, 36, 733-739. doi:10.1007/s10803006-0121-2.

Bolger, K. E., \& Patterson, C. J. (2003). Sequelae of child maltreatment. In S. S. Luthar (Ed.), Resilience and vulnerability: adaptation in the context of childhood adversities. UK: Cambridge University Press.

Bolton, P. F., Murphy, M., Macdonald, H., Whitlock, B., Pickles, A., \& Rutter, M. (1997). Obstetric complications in autism: consequences or causes of the condition? Journal of the Amercian Academy of Child and Adolescent Psychiatry, 36, 272-281. doi:10.1097/ 00004583-199702000-00018.

Bowlby, J. (1982). Attachment and loss: retrospect and prospect. The American Journal of Orthopsychiatry, 52, 664-678. doi:10.1111/j. 1939-0025.1982.tb01456.x.

Bridgett, D. J., Oddi, K. B., Laake, L. M., Murdock, K. W., \& Bachmann, M. N. (2012). Integrating and differentiating aspects of self-regulation: effortful control, executive functioning, and links to negative affectivity. Emotion, 13, 47-63. doi:10.1037/a0029536.

Bronson, M. (2000). Self-regulation in early childhood: nature and nurture. New York: Guilford Press.

Brumariu, L. E., \& Kerns, K. A. (2010). Parent-child attachment and internalizing symptoms in childhood and adolescence: a review of empirical findings and future directions. Development and Psychopathology, 22, 177-203. doi:10.1017/S0954579409990344.

Bugental, D. B., Martorell, G. A., \& Barraza, V. (2003). The hormonal costs of subtle forms of infant maltreatment. Hormones and Behaviour, 43, 237-244. doi:10.1037/a0014031.

Burke, H. M., Davis, M. C., Otte, C., \& Mohr, D. C. (2005). Depression and cortisol responses to psychological stress: a meta-analysis. Psychoneuroendocrinology, 30, 846-856. doi:10.1016/j.psyneuen. 2005.02.010.

Cantwell, D., Baker, L., \& Rutter, M. (Eds.). (1976). Family factors. New York: Plenum Press.

Capps, L., Sigman, M., \& Mundy, P. (1994). Attachment security in children with autism. Development and Psychopathology, 6, 249261. doi:10.1017/S0954579400004569.

Carlson, S. M., Mandell, D. J., \& Williams, L. (2004a). Executive function and theory of mind: stability and prediction from ages 2 to 3 . Developmental Psychology, 40, 1105-1122. doi:10.1037/00121649.40.6.1105 1105 .

Carlson, S. M., Moses, L. J., \& Claxton, L. J. (2004b). Individual differences in executive functioning and theory of mind: an investigation of inhibitory control and planning ability. Journal of Experimental Child Psychology, 87(4), 299-319.

Carper, R. A., Moses, P., Tigue, Z. D., \& Courchesne, E. (2002). Cerebral lobes in autism: early hyperplasia and abnormal age effects. NeuroImage, 16, 1038-1051. doi:10.1006/nimg.2002.1099.

Cassel, T. D., Messinger, D. S., Ibanez, L. V., Haltigan, J. D., Acosta, S. I., \& Buchman, A. C. (2007). Early social and emotional communication in the infant siblings of children with autism spectrum disorders: an examination of the broad phenotype. Journal of Autism and Developmental Disorders, 37, 122-132. doi:10.1007/s10803-0060337-1.

Chandler, F., \& Dissanayake, C. (2013). An investigation of the security of caregiver attachment during middle childhood in children with high-functioning autistic disorder. Autism, 18, 485-492. doi:10. $1177 / 1362361313486205$.

Charman, T., \& Baird, G. (2002). Practitioner review: diagnosis of autism spectrum disorder in 2- and 3-year-old children. Journal of Child Psychology and Psychiatry, 43(3), 289-305.

Chugani, H. T., Behen, M. E., Muzik, O., Juhasz, C., Nagy, F., \& Chugani, D. C. (2001). Local brain functional activity following early deprivation: a study of postinstitutionalized Romanian orphans. NeuroImage, 14, 1290-1301. doi:10.1006/nimg.2001.0917.

Colonnesi, C., Draijer, E. M., Jan, J. M., Stams, G., Van der Bruggen, C. O., Bogels, S. M., \& Noom, M. J. (2011). The relation between 
insecure attachment and child anxiety: a meta-analytic review. Journal of Clinical Child and Adolescent Psychology, 40, 630 645. doi:10.1080/15374416.2011.581623.

Cook, R., Brewer, R., Shah, P., \& Bird, G. (2013). Alexithymia, not autism, predicts poor recognition of emotional facial expressions. Psychological Science, 24, 723-732. doi:10.1177/ 0956797612463582.

Corbett, B. A., Mendoza, S., Abdullah, M., Wegelin, J. A., \& Levine, S. (2006). Cortisol circadian rhythms and response to stress in children with autism. Psychoneuroendocrinology, 31, 59-68. doi:10.1007/ s10803-008-0575-5.

Corbett, B. A., Mendoza, S., Wegelin, J. A., Carmean, V., \& Levine, S. (2008). Variable cortisol circadian rhythms in children with autism and anticipatory stress. Journal of Psychiatry and Neuroscience, 33, 227-234. doi:10.3410/f.1147891.604983.

Corbett, B. A., Schupp, C. W., Levine, S., \& Mendoza, S. (2009). Comparing cortisol, stress, and sensory sensitivity in children with autism. Autism Research, 2, 39-49. doi:10.1002/aur.64.

Corbett, B. A., Schupp, C. W., Simon, D., Ryan, N., \& Mendoza, S. (2010). Elevated cortisol during play is associated with age and social engagement in children with autism. Molecular Autism, 1, 13. doi:10.1186/2040-2392-1-13.

Corona, R., Dissanayake, C., Arbelle, S., Wellington, P., \& Sigman, M. (1998). Is affect aversive to young children with autism? Behavioral and cardiac responses to experimenter distress. Child Development, 69, 1494-1502. doi:10.2307/1132127.

Courchesne, E., Pierce, K., Schumann, C. M., Redcay, E., Buckwalter, J. A., Kennedy, D. P., et al. (2007). Mapping early brain development in autism. Neuron, 56(2), 399-413. Retrieved from: http://www. ncbi.nlm.nih.gov/pubmed/17964254.

Curin, J. M., Terzic, J., Petkovic, Z. B., Zekan, L., Terzic, I. M., Susnjara, I. M. (2003). Lower cortisol and higher ACTH levels in individuals with autism. Journal of Autism and Developmental Disorders, 33(4), 443-448. Retrieved from http://www.ncbi.nlm.nih.gov/ pubmed/12959423.

Czapinski, P., \& Bryson, S. E. (2003). Reduced facial muscles movements in autism: evidence for dysfunction in the neuromuscular pathway. Brain and Cognition, 51(2), 177-179.

Dallaire, D. H., \& Weinraub, M. (2007). Infant-mother attachment security and children's anxiety and aggression at first grade. Journal of Applied Developmental Psychology, 29, 477-492. doi:10.1016/j. appdev.2007.06.005.

Dalton, K. M., Nacewicz, B. M., Johnstone, T., Schaefer, H. S., Gernsbacher, M. A., Goldsmith, H. H., et al. (2005). Gaze fixation and the neural circuitry of face processing in autism. Nature Neuroscience, 8, 519-526. doi:10.1038/nn1421.

Davis, N. O., \& Carter, A. S. (2008). Parenting stress in mothers and fathers of toddlers with autism spectrum disorders: associations with child characteristics. Journal of Autism and Developmental Disorders, 38, 1278-1291. doi:10.1007/s10803-007-0512-z.

Dawson, G. (2008). Early behavioral intervention, brain plasticity, and the prevention of autism spectrum disorder. Development and Psychopathology, 20, 775-803. doi:10.1017/S0954579408000370.

Dawson, G., Carver, L., Meltzoff, A. N., Panagiotides, H., McPartland, J., \& Webb, S. J. (2002). Neural correlates of face and object recognition in young children with autism spectrum disorder, developmental delay, and typical development. Child Development, 73, 700717. doi:10.1111/1467-8624.00433.

Dawson, G., Webb, S. J., Carver, L., Panagiotides, H., \& McPartland, J. (2004). Young children with autism show atypical brain responses to fearful versus neutral facial expressions of emotion. Developmental Science, 7, 340-359. doi:10.1111/j.1467-7687.2004.00352.x.

De Bellis, M. D., \& Kuchibhatla, M. (2006). Cerebellar volumes in pediatric maltreatment-related posttraumatic stress disorder. Biological Psychiatry, 60, 697-703. doi:10.1016/j.biopsych.2006.04.035.
Degnan, K. A., \& Fox, N. A. (2007). Behavioral inhibition and anxiety disorders: multiple levels of a resilience process. Development and Psychopathology, 19, 729-746. doi:10.1017/S0954579407000363.

Demurie, E., De Corel, M., \& Roeyers, H. (2011). Empathic accuracy in adolescents with autism spectrum disorders and adolescents with attention-deficit/hyperactivity disorder. Research in Autism Spectrum Disorders, 5, 126-134. doi:10.1016/j.rasd.2010.03.002.

D'Esposito, M. (2007). From cognitive to neural models of working memory. Philosophical Transactions of the Royal Society of London. Series B, Biological Sciences, 362, 761-772. doi:10. 1098/rstb.2007.2086.

Di Martino, A., Ross, K., Uddin, L. Q., Sklar, A. B., Castellanos, F. X., \& Milham, M. P. (2009). Functional brain correlates of social and nonsocial processes in autism spectrum disorders: an activation likelihood estimation meta-analysis. Biological Psychiatry, 65, 63-74. doi:10.1016/j.biopsych.2008.09.022.

Dodge, K. A., Pettit, G. S., Bates, J. E., \& Valente, E. (1995). Social information-processing patterns partially mediate the effect of early physical abuse on later conduct problems. Journal of Abnormal Psychology, 104, 632-643. doi:10.1037/0021-843X.104.4.632.

Doussard-Roosevelt, J. A., Joe, C. M., Bazhenova, O. V., \& Porges, S. W. (2003). Mother-child interaction in autistic and nonautistic children: characteristics of maternal approach behaviors and child social responses. Development and Psychopathology, 15, 277-295. doi:10. 1017/S0954579403000154.

Downs, A., \& Smith, T. (2004). Emotional understanding, cooperation, and social behavior in high-functioning children with autism. Journal of Autism and Developmental Disorders, 34, 625-635. doi:10.1007/s10803-004-5284-0.

Dozier, M., Peloso, E., Lewis, E., Laurenceau, J. P., \& Levine, S. (2008). Effects of an attachment-based intervention on the cortisol production of infants and toddlers in foster care. Development and Psychopathology, 20, 845-859. doi:10.1017/S0954579408000400.

Dubois-Comtois, K., Moss, E., Cyr, C., \& Pascuzzo, K. (2013). Behavior problems in middle childhood: the predictive role of maternal distress, child attachment, and mother-child interactions. Journal of Abnormal Child Psychology, 41, 1311-1324. doi:10.1007/s10802013-9764-6.

Dziobek, I., Fleck, S., Kalbe, E., Rogers, K., Hassenstab, J., Brand, M., \& Convit, A. (2006). Introducing MASC: a movie for the assessment of social cognition. Journal of Autism and Developmental Disorders, 36, 623-636. doi:10.1007/s10803-006-0107-0.

Elfenbein, H. A., \& Ambady, N. (2002). On the universality and cultural specificity of emotion recognition: a meta-analysis. Psychological Bulletin, 128(2), 203-235. doi: 10.10371/0033-2909.1282.203.

Enticott, P. G., Rinehart, N. J., Tonge, B. J., Bradshaw, J. L., \& Fitzgerald, P. B. (2010). A preliminary transcranial magnetic stimulation study of cortical inhibition and excitability in high-functioning autism and Asperger disorder. Developmental Medicine and Child Neurology, 52, 179-183. doi:10.1111/j.1469-8749.2010.03665.x.

Evers, K., Kerkhof, I., Steyaert, J., Noens, I., \& Wagemans, J. (2014). No differences in emotion recognition in children with autism spectrum disorder: evidence from hybrid faces. Autism Research and Treatment, 2014, 1-8. doi:10.1155/2014/345878.

Fasihi, R., Hasanzadeh, R., Mahmoudi, G. (2013). Correlation between attachment style and alexithymia in university students, Journal of Psychology and Behavioural Studies, 1(1), 11-17. Retrieved from http://www.jpbsjournal.com/wp-content/uploads/paper21.pdf.

Fearon, R. M. P., \& Belsky, J. (2011). Infant-mother attachment and the growth of externalizing problems across the primary-school years. Journal of Child Psychology and Psychiatry, 52, 782-791. doi:10. 1111/j.1469-7610.2010.02350.x.

Fearon, R. M. P., Bakermans-Kranenburg, M. J., van Ijzendoorn, M. H., Lapsley, A. M., \& Roisman, G. I. (2010). The significance of insecure attachment and disorganization in the development of children's externalizing behavior: a meta-analytic study. Child 
Development, 81, 435-456. doi:10.1111/j.1467-8624.2009.01405. $\mathrm{x}$.

Federenko, I. S., Nagamine, M., Hellhammer, D. H., Wadhwa, P. D., \& Wust, S. (2004). The heritability of hypothalamus pituitary adrenal axis responses to psychosocial stress is context dependent. The Journal of Clinical Endocrinology and Metabolism, 89, 62446250. doi:10.1210/jc.2004-0981.

Feldman, R., Eidelman, A. I., \& Rotenberg, N. (2004). Parenting stress, infant emotion regulation, maternal sensitivity, and the cognitive development of triplets: a model for parent and child influences in a unique ecology. Child Development, 75, 1774-1791. doi:10.1111/ j.1467-8624.2004.00816.x

Fonagy, P., \& Target, M. (1997). Attachment and reflective function: their role in self-organization. Development and Psychopathology, 9, 679-700. doi:10.1017/S0954579497001399.

Fonagy, P., Steele, M., \& Steele, H. (1991). The capacity for understanding mental states: the reflective self in parent and child and its significance for security of attachment. Infant Mental Health Journal, 12, 201-218. doi:10.1002/1097-0355.

Fox, N. A. (1994). Dynamic cerebral processes underlying emotion regulation. Monographs of the Society for Research in Child Development, 59, 152-166. doi:10.1111/j.1540-5834.1994. tb01282.x.

Fox, N. A., Calkins, S. D., \& Bell, M. A. (1994). Neural plasticity and development in the first two years of life: evidence from cognitive and socio-emotional domains of research. Development and Psychopathology, 6, 677-698. doi:10.1177/0165025413516257.

Fox, A. S., Shelton, S. E., Oakes, T. R., Davidson, R. J., \& Kalin, N. H. (2008). Trait-like brain activity during adolescence predicts anxious temperament in primates. PLoS One, 3(7), e2570. doi:10.1371/ journal.pone.0002570.

Frey, S., \& Petrides, M. (2000). Orbitofrontal cortex: a key prefrontal region for encoding information. Proceedings of the National Academy of Sciences of the United States of America, 97, 87238727. doi:10.1073/pnas.140543497.

Garon, N., Bryson, S. E., Zwaigenbaum, L., Smith, I. M., Brian, J., Roberts, W., \& Szatmari, P. (2009). Temperament and its relationship to autistic symptoms in a high-risk infant sib cohort. Journal of Abnormal Child Psychology, 37, 59-78. doi:10.1007/s10802-0089258-0.

Gilotty, L., Kenworthy, L., Sirian, L., Black, D. O., \& Wagner, A. E. (2002). Adaptive skills and executive function in autism spectrum disorders. Child Neuropsychology: A Journal on Normal and Abnormal Development in Childhood and Adolescence, 8, 241248. doi:10.1076/chin.8.4.241.13504.

Glasson, E. J., Bower, C., Petterson, B., de Klerk, N., Chaney, G., \& Hallmayer, J. F. (2004). Perinatal factors and the development of autism: a population study. Archives of General Psychiatry, 61, 618-627. doi:10.1001/archpsyc.61.6.618.

Goldberg, M. C., Mostofsky, S. H., Cutting, L. E., Mahone, E. M., Astor, B. C., Denckla, M. B., et al. (2005). Subtle executive impairment in children with autism and children with ADHD. Journal of Autism and Developmental Disorders, 35, 279-293. doi:10.1007/s10803005-3291-4.

Gordon, A. C., \& Olson, D. R. (1998). The relation between acquisition of a theory of mind and the capacity to hold in mind. Journal of Experimental Child Psychology, 68, 70-83. doi:10.1006/jecp.1997. 2423.

Green, J., \& Goldwyn, R. (2002). Annotation: attachment disorganisation and psychopathology: new findings in attachment research and their potential implications for developmental psychopathology in childhood. Journal of Child Psychology and Psychiatry, 43, 835-846. doi:10.1111/1469-7610.00102.

Groh, A. M., Roisman, G. I., van Ijzendoorn, M. H., BakermansKranenburg, M. J., \& Fearon, R. P. (2012). The significance of insecure and disorganized attachment for children's internalizing symptoms: a meta-analytic study. Child Development, 83, 591610. doi:10.1111/j.1467-8624.2011.01711.x.

Grossman, J. B., Klin, A., Carter, A. S., \& Volkmar, F. R. (2000). Verbal bias in recognition of facial emotions in children with Asperger syndrome. Journal of Child Psychology and Psychiatry, 41, 369379. doi:10.1111/1469-7610.00621.

Grossmann, K. E., Grossmann, K., \& Waters, E. (Eds.). (2005). Attachment from infancy to adulthood. New York: Guilford Press.

Grzadzinski, R. L., Luyster, R., Spencer, A. G., \& Lord, C. (2014). Attachment in young children with autism spectrum disorders: an examination of separation and reunion behaviors with both mothers and fathers. Autism, 18, 85-96. doi:10.1177/1362361312467235.

Gunnar, M. R., \& Fisher, P. A. (2006). Bringing basic research on early experience and stress neurobiology to bear on preventive interventions for neglected and maltreated children. Development and Psychopathology, 18, 651-677. d o i : 10.10170S0954579406060330.

Gunnar, M., \& Quevedo, K. (2007). The neurobiology of stress and development. Annual Review of Psychology, 58, 145-173. doi:10. 1146/annurev.psych.58.110405.085605.

Gunnar, M. R., \& Vazquez, D. M. (2001). Low cortisol and a flattening of expected daytime rhythm: potential indices of risk in human development. Development and Psychopathology, 13(3), 515-538. Retrieved from http://www.ncbi.nlm.nih.gov/pubmed/11523846.

Gunnar, M. R., Larson, M. C., Hertsgaard, L., Harris, M. L., \& Brodersen, L. (1992). The stressfulness of separation among nine-month-old infants: effects of social context variables and infant temperament. Child Development, 63, 290-303. doi:10.1111/j.1467-8624.1992. tb01627.x.

Gunnar, M. R., Sebanc, A. M., Tout, K., Donzella, B., van Dulmen, M. M. (2003). Peer rejection, temperament, and cortisol activity in preschoolers. Developmental Psychobiology, 43(4), 346-358. Retrieved from http://www.ncbi.nlm.nih.gov/pubmed/15027418.

Happe, F. G. (1993). Communicative competence and theory of mind in autism: a test of relevance theory. Cognition, 48, 101-119. doi:10. 1016/0010-0277(93)90026-R.

Happe, F. G. (1995). The role of age and verbal ability in the theory of mind task performance of subjects with autism. Child Development, 66, 843-855. doi:10.2307/1131954.

Harms, M. B., Martin, A., \& Wallace, G. L. (2010). Facial emotion recognition in autism spectrum disorders: a review of behavioral and neuroimaging studies. Neuropsychological Review, 20, 290322. doi:10.1007/s11065-010-9138-6.

Harris, G. J., Chabris, C. F., Clark, J., Urban, T., Aharon, I., Steele, S., \& Tager-Flusberg, H. (2006). Brain activation during semantic processing in autism spectrum disorders via functional magnetic resonance imaging. Brain and Cognition, 61, 54-68. doi:10.1016/j. bandc.2005.12.015.

Hastings, P. D., Shirtcliff, E. A., Klimes-Dougan, B., Allison, A. L., Derose, L., Kendziora, K. T., \& Zahn-Waxler, C. (2011). Allostasis and the development of internalizing and externalizing problems: changing relations with physiological systems across adolescence. Development and Psychopathology, 23, 1149-1165. doi: 10.1017/S0954579411000538.

Hatzinger, M., Brand, S., Perren, S., von Wyl, A., von Klitzing, K., \& Holsboer-Trachsler, E. (2007). Hypothalamic-pituitaryadrenocortical (HPA) activity in kindergarten children: importance of gender and associations with behavioral/emotional difficulties. Journal of Psychiatric Research, 41, 861-870. doi:10.1016/j. jpsychires.2006.07.012.

Hazlett, H. C., Poe, M., Gerig, G., Smith, R. G., Provenzale, J., Ross, A., et al. (2005). Magnetic resonance imaging and head circumference study of brain size in autism: birth through age 2 years. Archives of General Psychiatry, 62, 1366-1376. doi:10.1001/archpsyc.62.12. 1366. 
Heerey, E. A., Keltner, D., \& Capps, L. M. (2003). Making sense of selfconscious emotion: linking theory of mind and emotion in children with autism. Emotion, 3, 394-400. doi:10.1037/1528-3542.3.4.394.

Herba, C. M., Landau, S., Russell, T., Ecker, C., \& Phillips, M. L. (2006). The development of emotion-processing in children: effects of age, emotion, and intensity. Journal of Child Psychology and Psychiatry, and Allied Disciplines, 47, 1098-1106. doi:10.1080/ 13803390802255635.

Hill, E. L. (2004). Executive dysfunction in autism. Trends in Cognitive Sciences, 8, 26-32. doi:10.1016/j.tics.2003.11.003.

Hill, E. L., \& Frith, U. (2003). Understanding autism: insights from mind and brain. Philosophical Transactions of the Royal Society of London. Series B, Biological Sciences, 358, 281-289. doi:10. 1098/rstb.2002.1209.

Ho, B. P. V., Stephenson, J., Carter, M. (2012). Anger in children with autism spectrum disorder: parent's perspective. International Journal of Special Education, 27(2), 14-31. Retrieved from http:// files.eric.ed.gov/fulltext/EJ982857.pdf.

Hobson, R. P. (1986). The autistic child's appraisal of expressions of emotion. Journal of Child Psychology and Psychiatry, 27, 321342. doi:10.1111/j.1469-7610.1986.tb00191.x.

Hobson, R. P., \& Lee, A. (1989). Emotion-related and abstract concepts in autistic people: evidence from the British Picture Vocabulary Scale. Journal of Autism and Developmental Disorders, 19, 601-623. doi: 10.1007/BF02212860.

Hobson, R. P., \& Lee, A. (1998). Hello and goodbye: a study of social engagement in autism. Journal of Autism and Developmental Disorders, 28, 117-127. doi:10.1023/A:1026088531558.

Hultman, C. M., Sparen, P., \& Cnattingius, S. (2002). Perinatal risk factors for infantile autism. Epidemiology, 13(4), 417-423. doi:10. 1542/peds. 2008-3582.

Ip, P., Wong, V., Ho, M., Lee, J., \& Wong, W. (2004). Mercury exposure in children with autistic spectrum disorder: case-control study. Journal of Child Neurology, 19, 431-434. doi:10.1177/ 088307380401900606.

Jackson, M., \& Tisak, M. S. (2001). Is prosocial behaviour a good thing? Developmental changes in children's evaluations of helping, sharing, cooperating, and comforting. British Journal of Developmental Psychology, 19, 349-367. doi:10.1348/026151001166146.

Jaedicke, S., Storoschuk, S., \& Lord, C. (1994). Subjective experience and causes of affect in high-functioning children and adolescents with autism. Development and Psychopathology, 6, 273-284. doi: 10.1017/S0954579400004582.

Jahromi, L. B., Meek, S. E., \& Ober-Reynolds, S. (2012). Emotion regulation in the context of frustration in children with high functioning autism and their typical peers. Journal of Child Psychology and Psychiatry, 53, 1250-1258. doi:10.1111/j.1469-7610.2012.02560.x.

Jones, C. D., \& Schwartz, I. S. (2009). When asking questions is not enough: an observational study of social communication differences in high functioning children with autism. Journal of Autism and Developmental Disorders, 39, 432-443. doi:10.1007/s10803-0080642-y.

Joseph, R. M., \& Tager-Flusberg, H. (1997). An investigation of attention and affect in children with autism and Down syndrome. Journal of Autism and Developmental Disorders, 27, 385-396. doi:10.1023/ A:1025853321118.

Joseph, R. M., \& Tager-Flusberg, H. (2004). The relationship of theory of mind and executive functions to symptom type and severity in children with autism. Development and Psychopathology, 16, 137-155. doi:10.1017/S095457940404444X.

Joseph, R. M., Tager-Flusberg, H., \& Lord, C. (2002). Cognitive profiles and social-communicative functioning in children with autism spectrum disorder. Journal of Child Psychology and Psychiatry, 43, 807-821. doi:10.1111/1469-7610.00092.

Just, M. A., Cherkassky, V. L., Keller, T. A., Kana, R. K., \& Minshew, N. J. (2007). Functional and anatomical cortical underconnectivity in autism: evidence from an FMRI study of an executive function task and corpus callosum morphometry. Cerebral Cortex, 17, 951-961. doi:10.1093/cercor/bhl006.

Kanne, S. M., Abbacchi, A. M., \& Constantino, J. N. (2009). Multiinformant ratings of psychiatric symptom severity in children with autism spectrum disorders: the importance of environmental context. Journal of Autism and Developmental Disorders, 39, 856864. doi:10.1007/s10803-009-0694-7.

Kaufman, J., \& Charney, D. (2001). Effects of early stress on brain structure and function: implications for understanding the relationship between child maltreatment and depression. Development and Psychopathology, 13, 451-471. doi:10.1017/S0954579401003030.

Keenan, T., Olson, D. R., \& Marini, Z. (1998). Working memory and children's developing understanding of mind. Australian Journal of Psychology, 50, 76-82. doi:10.1080/00049539808257537.

Kemper, T. L., \& Bauman, M. L. (1993). The contribution of neuropathologic studies to the understanding of autism. Neurologic Clinics, 11(1), 175-187. Retrieved from: http://www.ncbi.nlm.nih.gov/ pubmed/8441369.

Kempuraj, D., Asadi, S., Zhang, B., Manola, A., Hogan, J., Peterson, E., $\&$ Theoharides, T. C. (2010). Mercury induces inflammatory mediator release from human mast cells. Journal of Neuroinflammation, 7, 20. doi:10.1186/1742-2094-7-20.

Kennedy, J. S., \& Lawrence, D. A. (2011). Coincidental associations do not provide proof for the etiology of autism. Journal of Immunotoxicology, 8, 198-203. doi:10.3109/1547691X.2011.584920.

Kinney, D. K., Munir, K. M., Crowley, D. J., \& Miller, A. M. (2008). Prenatal stress and risk for autism. Neuroscience and Biobehavioural Reviews, 32, 1519-1532. doi:10.1016/j.neubiorev. 2008.06.004.

Kleinhans, N. M., Richards, T., Sterling, L., Stegbauer, K. C., Mahurin, R., Johnson, L. C., \& Aylward, E. (2008). Abnormal functional connectivity in autism spectrum disorders during face processing. Brain, 131, 1000-1012. doi:10.1093/brain/awm334.

Klin, A. (2000). Attributing social meaning to ambiguous visual stimuli in higher-functioning autism and Asperger syndrome: the social attribution task. Journal of Child Psychology and Psychiatry, and Allied Disciplines, 41, 831-846. doi:10.1111/1469-7610.00671.

Kolevzon, A., Gross, R., \& Reichenberg, A. (2007). Prenatal and perinatal risk factors for autism: a review and integration of findings. Archives of Pediatrics \& Adolescent Medicine, 161, 326-333. doi: 10.1001/archpedi.161.4.326.

Konstantareas, M. M., \& Stewart, K. (2006). Affect regulation and temperament in children with autism spectrum disorder. Journal of Autism and Developmental Disorders, 36, 143-154. doi:10.1007/ s10803-005-0051-4.

Kovacs, M., \& Devlin, B. (1998). Internalizing disorders in childhood. Journal of Child Psychology and Psychiatry, 39, 47-63. doi:10. 1111/1469-7610.00303.

Kuusikko, S., Haapsamo, H., Jansson-Verkasalo, E., Hurtig, T., Mattila, M. L., Ebeling, H., \& Moilanen, I. (2009). Emotion recognition in children and adolescents with autism spectrum disorders. Journal of Autism and Developmental Disorders, 39, 938-945. doi:10.1007/ s10803-009-0700-0.

Laghi, F., Baiocco, R., Cannoni, E., Di Norcia, A., Baumgartner, E., \& Bombi, A. S. (2013). Friendship in children with internalizing and externalizing problems: a preliminary investigation with the pictorial assessment of interpersonal relationships. Children and Youth Services Review, 35, 1095-1100. doi:10.1016/j.childyouth.2013. 05.007 .

Lee, V., \& Hoaken, P. N. (2007). Cognition, emotion, and neurobiological development: mediating the relation between maltreatment and aggression. Child Maltreatment, 12, 281-298. doi:10.1177/ 1077559507303778.

Lerner, M. D., Mikami, A. Y., \& Levine, K. (2011). Socio-dramatic affective-relational intervention for adolescents with asperger 
syndrome \& high functioning autism: pilot study. Autism, 15, 2142. doi:10.1177/1362361309353613.

Lerner, M. D., McPartland, J. C., \& Morris, J. P. (2013). Multimodal emotion processing in autism spectrum disorders: an event-related potential study. Developmental Cognitive Neuroscience, 3, 11-21. doi:10.1016/j.den.2012.08.005.

Leslie, A. M., \& Frith, U. (1990). Prospects for a cognitive neuropsychology of autism: Hobson's choice. Psychological Review, 97, 122131. doi:10.1037/0033-295X.97.1.122.

Levine, T. P., Sheinkopf, S. J., Pescosolido, M., Rodino, A., Elia, G., \& Lester, B. (2012). Physiologic arousal to social stress in children with autism spectrum disorders: a pilot study. Research in Autism Spectrum Disorders, 6, 177-183. doi:10.1016/j.rasd.2011.04.003.

Lipton, M., \& Nowicki, S. (2009). The social emotional learning framework (SELF): a guide for understanding brain-based social emotional learning impairments. The Journal of Developmental Processes, 4, 99-115. doi:10.1037/a0033435.

Liu, K., Zerubavel, N., Bearman, P. (2010). Social demographic change and autism. Demography, 47, 327-343. Retrieved from: http:// www.ncbi.nlm.nih.gov/pmc/articles/PMC3000023/.

Loveland, K. (2005). Social-emotional impairment and self-regulation in Autism spectrum disorders. In J. Nadel \& D. Muir (Eds.), Typical and impaired emotional development (pp. 365-382). Oxford: Oxford University Press.

Loveland, K. A., Pearson, D. A., Tunali-Kotoski, B., Ortegon, J., \& Gibbs, M. C. (2001). Judgments of social appropriateness by children and adolescents with autism. Journal of Autism and Developmental Disorders, 31, 367-376. doi:10.1023/A:1010608518060.

Lyons, A. M., Leon, S. C., Roecker Phelps, C. E., \& Dunleavy, A. M. (2010). The impact of child symptom severity on stress among parents of children with ASD: the moderating role of coping styles. Journal of Child and Family Studies, 19, 516-524. doi:10.1177/ 1088357614537352.

Main, M. \& Solomon, J. (1986). Discovery of a new, insecure-disorganized/disoriented attachment pattern. In T. B. Brazelton \& M. Yogman (Eds), Affective development in infancy, pp. 95-124. Norwood, New Jersey: Ablex.

Malatesta, C. Z., \& Haviland, J. M. (1982). Learning display rules: the socialization of emotion expression in infancy. Child Development, 53, 991-1003. doi:10.1111/j.1467-8624.1982.tb01363.x.

Marinovic-Curin, J., Marinovic-Terzic, I., Bujas-Petkovic, Z., Zekan, L., Skrabic, V., Dogas, Z., et al. (2008). Slower cortisol response during ACTH stimulation test in autistic children. European Child \& Adolescent Psychiatry, 17, 39-43. doi:10.1007/s00787-007-0632-1.

Maskey, M., Warnell, F., Parr, J., LeCouteur, A., \& McConachie, H. (2013). Emotional and behavioural problems in children with autism spectrum disorder. Journal of Autism and Developmental Disorders, 43, 851-859. doi:10.1007/s10803-012-1622-9.

Mathersul, D., Palmer, D. M., Gur, R. C., Gur, R. E., Cooper, N., Gordon, E., \& Williams, L. M. (2009). Explicit identification and implicit recognition of facial emotions: II. Core domains and relationships with general cognition. Journal of Clinical and Experimental Neuropsychology, 31, 278-291. doi:10.1080/13803390802043619.

Matson, J., \& Nebel-Schwalm, M. (2007). Comorbid psychopathology with autism spectrum disorder in children: an overview. Research in Developmental Disabilities, 28, 341-352. doi:10.1016/j.ridd.2005.12.004.

Matson, J., Wilkins, J., \& Macken, J. (2008). The relationship of challenging behaviors to severity and symptoms of autism spectrum disorders. Journal of Mental Health Research in Intellectual Disabilities, 2, 29-44. doi:10.1080/19315860802611415.

Maughan, A., \& Cicchetti, D. (2002). Impact of child maltreatment and interadult violence on children's emotion regulation abilities and socioemotional adjustment. Child Development, 73, 1525-1542. doi:10.1111/1467-8624.00488

Mazefsky, C. A., Herrington, J., Siegel, M., Scarpa, A., Maddox, B. B., Scahill, L., \& White, S. W. (2013). The role of emotion regulation in autism spectrum disorder. Journal of the American Academy of Child and Adolescent Psychiatry, 52, 679-688. doi:10.1016/j.jaac. 2013.05.006.

Mazzone, L., Ruta, L., \& Reale, L. (2012). Psychiatric comorbidities in asperger syndrome and high functioning autism: diagnostic challenges. Annals of General Psychiatry, 11, 16. doi:10.1186/1744859X-11-16.

Mazzone, L., Postorino, V., De Peppo, L., Fatta, L., Lucarelli, V., Reale, L., \& Vicari, S. (2013). Mood symptoms in children and adolescents with autism spectrum disorders. Research in Developmental Disabilities, 34, 3699-3708. doi:10.1016/j.ridd.2013.07.034.

McCrory, E., De Brito, S. A., \& Viding, E. (2010). Research review: the neurobiology and genetics of maltreatment and adversity. Journal of Child Psychology and Psychiatry, and Allied Disciplines, 51, 10791095. doi:10.1111/j.1469-7610.2010.02271.x.

McKown, C., Gumbiner, L. M., Russo, N. M., \& Lipton, M. (2009). Social-emotional learning skill, self-regulation, and social competence in typically developing and clinic-referred children. Journal of Clinical Child and Adolescent Psychology, 38, 858-871. doi:10. 1080/15374410903258934.

McPartland, J., Dawson, G., Webb, S. J., Panagiotides, H., \& Carver, L. J. (2004). Event-related brain potentials reveal anomalies in temporal processing of faces in autism spectrum disorder. Journal of Child Psychology and Psychiatry, 45, 1235-1245. doi:10.1111/j.14697610.2004.00318.x.

Megson, M. N. (2000). Is autism a G-alpha protein defect reversible with natural vitamin A? Medical Hypotheses, 54, 979-983. doi:10.1054/ mehy.1999.0999.

Meins, E., Fernyhough, C., Fradley, E., \& Tuckey, M. (2001). Rethinking maternal sensitivity: mothers' comments on infants' mental processes predict security of attachment at 12 months. Journal of Child Psychology and Psychiatry, and Allied Disciplines, 42, 637-648. doi:10.1017/S0021963001007302.

Meyer, J. A., Mundy, P. C., Van Hecke, A. V., \& Durocher, J. S. (2006). Social attribution processes and comorbid psychiatric symptoms in children with Asperger syndrome. Autism: The International Journal of Research and Practice, 10, 383-402. doi:10.1177/ 1362361306064435.

Miyake, A., Friedman, N. P., Emerson, M. J., Witzki, A. H., Howerter, A., \& Wager, T. D. (2000). The unity and diversity of executive functions and their contributions to complex "Frontal Lobe" tasks: a latent variable analysis. Cognitive Psychology, 41, 49-100. doi:10. 1006/cogp.1999.0734.

Morgan, B., Maybery, M., \& Durkin, K. (2003). Weak central coherence, poor joint attention, and low verbal ability: independent deficits in early autism. Developmental Psychology, 39, 646-656. doi:10. 1037/0012-1649.39.4.646.

Moss, E., Smolla, N., Cyr, C., Dubois-Comtois, K., Mazzarello, T., \& Berthiaume, C. (2006). Attachment and behavior problems in middle childhood as reported by adult and child informants. Development and Psychopathology, 18, 425-444. doi:10.1017/ S0954579406060238.

Mundy, P., Sullivan, L., \& Mastergeorge, A. M. (2009). A parallel and distributed-processing model of joint attention, social cognition and autism. Autism Research: Official Journal of the International Society for Autism Research, 2, 2-21. doi:10.1002/aur.61.

Munson, J. A., McMahon, R. J., \& Spieker, S. J. (2001). Structure and variability in the developmental trajectory of children's externalizing problems: impact of infant attachment, maternal depressive symptomatology, and child sex. Development and Psychopathology, 13, 277-296. doi:10.1017/S095457940100205X.

Murias, M., Webb, S. J., Greenson, J., \& Dawson, G. (2007). Resting state cortical connectivity reflected in EEG coherence in individuals with autism. Biological Psychiatry, 62(3), 270-273. doi:10.1016/j. biopsych.2006.11.012. 
Naber, F. B., Swinkels, S. H., Buitelaar, J. K., Bakermans-Kranenburg, M. J., van Ijzendoorn, M. H., Dietz, C., \& van Engeland, H. (2007). Attachment in toddlers with autism and other developmental disorders. Journal of Autism and Developmental Disorders, 37, 11231138. doi:10.1007/s10803-006-0255-2.

Nadig, A. S., Ozonoff, S., Young, G. S., Rozga, A., Sigman, M., \& Rogers, S. J. (2007). A prospective study of response to name in infants at risk for autism. Archives of Pediatrics and Adolescent Medicine, 161, 378-383. doi:10.1001/archpedi.161.4.378.

Nelson, C. A., \& Bloom, F. E. (1997). Child development and neuroscience. Child Development, 68, 970-987. doi:10.1111/j.1467-8624. 1997.tb01974.x.

Neumann, D., Spezio, M. L., Piven, J., \& Adolphs, R. (2006). Looking you in the mouth: abnormal gaze in autism resulting from impaired top-down modulation of visual attention. Social Cognitive and Affective Neuroscience, 1, 194-202. doi:10.1093/scan/ns1030.

Ochsner, K. N., \& Gross, J. J. (2005). The cognitive control of emotion. Trends in Cognitive Sciences, 9, 242-249. doi:10.1016/j.tics.2005. 03.010 .

O’Connor, T. G., Heron, J., Golding, J., Glover, V., \& Team, A. S. (2003). Maternal antenatal anxiety and behavioural/emotional problems in children: a test of a programming hypothesis. Journal of Child Psychology and Psychiatry, 44, 1025-1036. doi:10.1111/14697610.00187.

Ozonoff, S., Iosif, A. M., Baguio, F., Cook, I. C., Hill, M. M., Hutman, T., et al. (2010). A prospective study of the emergence of early behavioral signs of autism. Journal of the American Academy of Child and Adolescent Psychiatry, 49, 256-266. doi:10.1016/j.jaac.2009.11. 009

Palomo, R., Belinchon, M., \& Ozonoff, S. (2006). Autism and family home movies: a comprehensive review. Journal of Developmental and Behavioural Paediatrics, 27, 59-68. doi:10.1097/00004703200604002-00003.

Parisi, M. A., Pinter, J. D., Glass, I. A., Field, K., Maria, B. L., Chance, P. F., et al. (2004). Cerebral and cerebellar motor activation abnormalities in a subject with Joubert syndrome: functional magnetic resonance imaging (MRI) study. Journal of Child Neurology, 19(3), 214-218. Retrieved from: http://www.ncbi.nlm.nih.gov/pubmed/ 15119482.

Pellicano, E., Maybery, M., Durkin, K., \& Maley, A. (2006). Multiple cognitive capabilities/deficits in children with an autism spectrum disorder: "weak" central coherence and its relationship to theory of mind and executive control. Development and Psychopathology, 18, 77-98. doi:10.1017/S0954579406060056.

Pelphrey, K. A., Sasson, N. J., Reznick, J. S., Paul, G., Goldman, B. D., \& Piven, J. (2002). Visual scanning of faces in autism. Journal of Autism and Developmental Disorders, 32, 249-261. doi:10.1023/ A:1016374617369.

Pennington, B. F., \& Ozonoff, S. (1996). Executive functions and developmental psychopathology. Journal of Child Psychology and Psychiatry, and Allied Disciplines, 37(1), 51-87. Retrieved from: http://www.ncbi.nlm.nih.gov/pubmed/8655658.

Phelps, K. W., Hodgson, J. L., McCammon, S. L., \& Lamson, A. L. (2009). Caring for an individual with autism disorder: a qualitative analysis. Journal of Intellectual and Developmental Disability, 34, 27-35. doi:10.1080/13668250802690930.

Pierce, K., Muller, R. A., Ambrose, J., Allen, G., \& Courchesne, E. (2001). Face processing occurs outside the fusiform 'face area' in autism: evidence from functional MRI. Brain, 124(2059-2073), 2059-2073. doi:10.1093/brain/124.10.2059.

Piggot, J., Kwon, H., Mobbs, D., Blasey, C., Lotspeich, L., Menon, V., et al. (2004). Emotional attribution in high-functioning individuals with autistic spectrum disorder: a functional imaging study. Journal of the American Academy of Child and Adolescent Psychiatry, 43, 473-480. doi:10.1097/00004583-200404000-00014.
Piggot, J., Shirinyan, D., Shemmassian, S., Vazirian, S., \& Alarcon, M. (2009). Neural systems approaches to the neurogenetics of autism spectrum disorders. Neuroscience, 164, 247-256. doi:10.1016/j. neuroscience.2009.05.054.

Porges, S. W., Doussard-Roosevelt, J. A., \& Maiti, A. K. (1994). Vagal tone and the physiological regulation of emotion. Monographs of the Society for Research in Child Development, 59, 167-186. doi: 10.1111/j.1540-5834.1994.tb01283.x.

Porges, S. W., Doussard-Roosevelt, J. A., Portales, A. L., \& Greenspan, S. I. (1996). Infant regulation of the vagal "brake" predicts child behavior problems: a psychobiological model of social behavior. Developmental Psychobiology, 29(8), 697-712.

Posner, M. I., \& Rothbart, M. K. (2000). Developing mechanisms of selfregulation. Development and Psychopathology, 12, 427-441. doi: 10.1017/S0954579400003096.

Presmanes, A. G., Walden, T. A., Stone, W. L., \& Yoder, P. J. (2007). Effects of different attentional cues on responding to joint attention in younger siblings of children with autism spectrum disorders. Journal of Autism and Developmental Disorders, 37, 133-144. doi:10.1007/s10803-006-0338-0.

Price, D. A., Close, G. C., \& Fielding, B. A. (1983). Age of appearance of circadian rhythm in salivary cortisol values in infancy. Archives of Disease in Childhood, 58, 454-456. doi:10.1136/adc.58.6.454.

Prior, M., Dahlstrom, B., \& Squires, T. L. (1990). Autistic children's knowledge of thinking and feeling states in other people. Journal of Child Psychology and Psychiatry, and Allied Disciplines, 31, 587-601. doi:10.1111/j.1469-7610.1990.tb00799.x.

Raikes, H. A., \& Thompson, R. A. (2006). Family emotional climate, attachment security and young children's emotion knowledge in a high risk sample. British Journal of Developmental Psychology, 24, 89-104. doi:10.1348/026151005X70427.

Ratajczak, H. V. (2011). Theoretical aspects of autism: causes - a review. Journal of Immunotoxicology, 8, 68-79. doi:10.3109/1547691X. 2010.545086.

Reddy, V., Williams, E., \& Vaughan, A. (2002). Sharing humour and laughter in autism and Down's syndrome. British Journal of Psychology, 93, 219-242. doi:10.1348/000712602162553.

Riby, D. M., \& Hancock, P. J. (2008). Viewing it differently: social scene perception in Williams syndrome and autism. Neuropsychologia, 46, 2855-2860. doi:10.1016/j.neuropsychologia.2008.05.003.

Richdale, A. L., \& Prior, M. R. (1992). Urinary cortisol circadian rhythm in a group of high-functioning children with autism. Journal of Autism and Developmental Disorders, 22, 433-447. doi:10.1007/ BF01048245.

Rieffe, C., Meerum Terwogt, M., \& Stockmann, L. (2000). Understanding atypical emotions among children with autism. Journal of Autism and Developmental Disorders, 30, 195-203. doi:10.1023/A:1005540417877.

Rieffe, C., Meerum Terwogt, M., \& Kotronopoulou, K. (2007). Awareness of single and multiple emotions in high-functioning children with autism. Journal of Autism and Developmental Disorders, 37, 455-465. doi:10.1007/s10803-006-0171-5.123.

Rieffe, C., Oosterveld, P., Terwogt, M. M., Mootz, S., van Leeuwen, E., \& Stockmann, L. (2011). Emotion regulation and internalizing symptoms in children with autism spectrum disorders. Autism, 15, 655-670. doi:10.1177/1362361310366571.

Rogers, S. J. (2009). What are infant siblings teaching us about autism in infancy? Autism Research, 2, 125-137. doi:10.1002/aur.81.

Rogers, S. J., Ozonoff, S., \& Maslin-Cole, C. (1993). Developmental aspects of attachment behavior in young children with pervasive developmental disorders. Journal of the American Academy of Child and Adolescent Psychiatry, 32, 1274-1282. doi:10.1097/ 00004583-199311000-00023.

Rogers, K., Dziobek, I., Hassenstab, J., Wolf, O. T., \& Convit, A. (2007). Who cares? Revisiting empathy in Asperger syndrome. Journal of 
Autism and Developmental Disorders, 37, 709-715. doi:10.1007/ s10803-006-0197-8.

Roque, L., Verissimo, M., Oliveira, T. F., \& Oliveira, R. F. (2012). Attachment security and HPA axis reactivity to positive and challenging emotional situations in child-mother dyads in naturalistic settings. Developmental Psychobiology, 54, 401-411. doi:10.1002/ dev.20598.

Rosenqvist, J., Lahti-Nuuttila, P., Laasonen, M., \& Korkman, M. (2014). Preschoolers' recognition of emotional expressions: relationships with other neurocognitive capacities. Child Neuropsychology, 20, 281-302. doi:10.1080/09297049.2013.778235.

Roskam, I., Meunier, J., \& Stievenart, M. (2011). Parent attachment, childrearing behavior, and child attachment: mediated effects predicting preschoolers' externalizing behavior. Journal of Applied Developmental Psychology, 32, 170-179. doi:10.1016/j.appdev. 2011.03.003

Rothbart, M. K., \& Sheese, B. E. (2007). Temperament and emotion regulation. In J. J. Gross (Ed.), Handbook of emotion regulation (pp. 331-350). New York: Guilford Press.

Roth-Hanania, R., Busch-Rossnagel, N., \& Higgins-D’Alessandro, A. (2000). Development of self and empathy in early infancy: implications for atypical development. Infants and Young Children, 13, 114. doi:10.1097/00001163-200013010-00004.

Ruffman, T., Slade, L., \& Crowe, E. (2002). The relation between children's and mothers' mental state language and theory-of-mind understanding. Child Development, 73, 734-751. doi:10.1111/14678624.00435 .

Rump, K. M., Giovannelli, J. L., Minshew, N. J., \& Strauss, M. S. (2009). The development of emotion recognition in individuals with autism. Child Development, 80, 1434-1447. doi:10.1111/j.1467-8624.2009. 01343.x.

Rutgers, A. H., Bakermans-Kranenburg, M. J., van Ijzendoorn, M. H., \& van Berckelaer-Onnes, I. A. (2004). Autism and attachment: a metaanalytic review. Journal of Child Psychology and Psychiatry, 45, 1123-1134. doi:10.1111/j.1469-7610.2004.t01-1-00305.x.

Rutgers, A. H., van Ijzendoorn, M. H., Bakermans-Kranenburg, M. J., Swinkels, S. H., van Daalen, E., Dietz, C., \& van Engeland, H. (2007). Autism, attachment and parenting: a comparison of children with autism spectrum disorder, mental retardation, language disorder, and non-clinical children. Journal of Abnormal Child Psychology, 35, 859-870. doi:10.1007/s10802-007-9139-y.

Saarni, C. (1999). The development of emotional competence. New York: Guilford Publications.

Samson, A. C., Huber, O., \& Gross, J. J. (2012). Emotion regulation in Asperger's syndrome and high-functioning autism. Emotion, 12, 659-665. doi:10.1037/a0027975.

Schore, A. N. (2000). Attachment and the regulation of the right brain. Attachment \& Human Development, 2, 23-47. doi:10.1080/ 146167300361309

Schore, A. N. (2002). Dysregulation of the right brain: a fundamental mechanism of traumatic attachment and the psychopathogenesis of posttraumatic stress disorder. The Australian and New Zealand Journal of Psychiatry, 36, 9-30. doi:10.1046/j.1440-1614.2002. 00996.x.

Schore, A. N. (2009). Attachment trauma and the developing right brain: Origins of pathological dissociation. In P. F. Dell \& J. A. O'Neil (Eds.), Dissociation and the dissociative disorders: DSM V and beyond. New York: Taylor \& Francis Group.

Schupp, C. W., Simon, D., \& Corbett, B. A. (2013). Cortisol responsivity differences in children with autism spectrum disorders during free and cooperative play. Journal of Autism and Developmental Disorders, 43, 2405-2417. doi:10.1007/s10803-013-1790-2.

Shields, A., Cicchetti, D., \& Ryan, R. M. (1994). The development of emotional and behavioral self regulation and social competence among maltreated school-age children. Development and Psychopathology, 6, 57-75. doi:10.1017/S0954579400005885.
Shirtcliff, E. A., \& Essex, M. J. (2008). Concurrent and longitudinal associations of basal and diurnal cortisol with mental health symptoms in early adolescence. Developmental Psychobiology, 50, 690703. doi:10.1002/dev.20336.

Shirtcliff, E. A., Granger, D. A., Booth, A., \& Johnson, D. (2005). Low salivary cortisol levels and externalizing behavior problems in youth. Development and Psychopathology, 17, 167-184. doi:10. 1017/S0954579400002017.

Shorey, H. S., \& Snyder, C. R. (2006). The role of adult attachment styles in psychopathology and psychotherapy outcomes. Review of General Psychology, 10, 1-20. doi:10.1037/1089-2680.10.1.1.

Sigman, M., \& Mundy, P. (1989). Social attachments in autistic children. Journal of the American Academy of Child and Adolescent Psychiatry, 28, 74-81. doi:10.1097/00004583-198901000-00014.

Sigman, M. D., Kasari, C., Kwon, J. H., \& Yirmiya, N. (1992). Responses to the negative emotions of others by autistic, mentally retarded, and normal children. Child Development, 63, 796-807. doi:10.1111/j. 1467-8624.1992.tb01662.x.

Simonoff, E., Pickles, A., Charman, T., Chandler, S., Loucas, T., \& Baird, G. (2008). Psychiatric disorders in children with autism spectrum disorders: prevalence, comorbidity, and associated factors in a population-derived sample. Journal of the American Academy of Child and Adolescent Psychiatry, 47, 921-929. doi:10.1097/CHI. 0b013e318179964f.

Slaughter, V., Peterson, C., \& Mackintosh, E. (2007). Mind what mother says: narrative input and theory of mind in typical children and those on the autism spectrum. Child Development, 78, 839-858. doi:10. 1111/j.1467-8624.2007.01036.

Smith, M., \& Walden, T. (1999). Understanding feelings and coping with emotional situations: a comparison of maltreated and nonmaltreated preschoolers. Social Development, 8, 93-116. doi:10.1111/14679507.00082.

Sofronoff, K., Attwood, T., Hinton, S., \& Levin, I. (2007). A randomized controlled trial of a cognitive behavioural intervention for anger management in children diagnosed with Asperger syndrome. Journal of Autism and Developmental Disorders, 37, 1203-1214. doi:10.1007/s10803-006-0262-3.

Sparks, B. F., Friedman, S. D., Shaw, D. W., Aylward, E. H., Echelard, D., Artru, A. A., \& Dager, S. R. (2002). Brain structural abnormalities in young children with autism spectrum disorder. Neurology, 59, 184 192. doi:10.1212/WNL.59.2.184.

Spinrad, T. L., Eisenberg, N., Harris, E., Hanish, L., Fabes, R. A., Kupanoff, K., et al. (2004). The relation of children's everyday nonsocial peer play behavior to their emotionality, regulation, and social functioning. Developmental Psychology, 40, 67-80. doi:10. 1037/0012-1649.40.1.67.

Sroufe, L. A. (1996). Emotional development: the organization of emotional life in the early years. New York: Cambridge University Press.

Steele, H., Steele, M., \& Croft, C. (2008). Early attachment predicts emotion recognition at 6 and 11 years old. Attachment \& Human Development, 10, 379-393. doi:10.1080/14616730802461409.

Steelman, L. M., Assel, M. A., Swank, P. R., Smith, K. E., Landry, S. H. (2002). Early maternal warm responsiveness as a predictor of child social skills: direct and indirect paths of influence over time. Journal of Applied Developmental Psychology, 23, 135-156. doi: 10.1016/ S0193-3973(02)00101-6.

Strang, J. F., Kenworthy, L., Daniolos, P., Case, L., Wills, M. C., Martin, A., \& Wallace, G. L. (2012). Depression and anxiety symptoms in children and adolescents with autism spectrum disorders without intellectual disability. Research in Autism Spectrum Disorders, 6 , 406-412. doi:10.1016/j.rasd.2011.06.015.

Strathearn, L. (2007). Exploring the neurobiology of attachment. In L. C. Mayes, P. Fonagy, \& M. Target (Eds.), Developmental science and psychoanalysis. London: Karnac Press. 
Tager-Flusberg, H. (1992). Autistic children's talk about psychological states: deficits in the early acquisition of a theory of mind. Child Development, 63, 161-172. doi:10.1111/j.1467-8624.1992. tb03604.x.

Tager-Flusberg, H. (2010). The origins of social impairments in autism spectrum disorder: studies of infants at risk. Neural Networks, 23, 1072-1076. doi:10.1016/j.neunet.2010.07.008.

Taumoepeau, M., \& Ruffman, T. (2008). Stepping stones to others' minds: maternal talk relates to child mental state language and emotion understanding at 15, 24, and 33 months. Child Development, 79, 284-302. doi:10.1111/j.1467-8624.2007.01126.x.

Toth, K., Dawson, G., Meltzoff, A. N., Greenson, J., \& Fein, D. (2007). Early social, imitation, play, and language abilities of young nonautistic siblings of children with autism. Journal of Autism and Developmental Disorders, 37, 145-157. doi:10.1007/s10803-0060336-2.

Tyrka, A. R., Carpenter, L. L., Carvalho, J. P., Price, L. H. (2006). Biomarkers in the human stress system: do they signal risk for depression? Medicine and Health, Rhode Island, 89(5), 180-182. Retrieved from http://www.ncbi.nlm.nih.gov/pubmed/16764301.

van Ijzendoorn, M. H., Schuengel, C., \& Bakermans-Kranenburg, M. J. (1999). Disorganized attachment in early childhood: meta-analysis of precursors, concomitants, and sequelae. Development and Psychopathology, 11, 225-249. doi:10. 1017/S0954579499002035.

van Ijzendoorn, M., Rutgers, A., Bakermans-Kranenburg, M., Swinkels, S., Van Daalen, E., Buitelaar, J., et al. (2007). Parental sensitivity and attachment in children with autism spectrum disorder: comparison with children with mental retardation, with language delays, and with typical development. Child Development, 78, 597-608. doi:10.1111/j.1467-8624.2007.01016.x.

Vollm, B. A., Taylor, A. N., Richardson, P., Corcoran, R., Stirling, J., McKie, S., \& Elliott, R. (2006). Neuronal correlates of theory of mind and empathy: a functional magnetic resonance imaging study in a nonverbal task. NeuroImage, 29, 90-98. doi:10.1016/j. neuroimage.2005.07.022.

Wakefield, A. J. (1998). MMR vaccination and autism. Lancet, 354(9182), 949-950.

Waters, S. F., Virmani, E. A., Thompson, R. A., Meyer, S., Raikes, H. A., \& Jochem, R. (2010). Emotion regulation and attachment: unpacking two constructs and their association. Journal of Psychopathology and Behavioural Assessment, 32, 37-47. doi:10. 1007/s10862-009-9163-z.

Wearden, A., Cook, L., Vaughan-Jones, J. (2003). Adult attachment, alexithymia, symptom -reporting, and health-related coping. Journal of Psychosomatic Research, 55(4), 341-347. Retrieved from http://www.ncbi.nlm.nih.gov/pubmed/14507545.

Webb, S. J., Dawson, G., Bernier, R., \& Panagiotides, H. (2006). ERP evidence of atypical face processing in young children with autism. Journal of Autism and Developmental Disorders, 36, 881-890. doi: 10.1007/s10803-006-0126-x.

Webb, S. J., Sparks, B. F., Friedman, S. D., Shaw, D. W., Giedd, J., Dawson, G., \& Dager, S. R. (2009). Cerebellar vermal volumes and behavioral correlates in children with autism spectrum disorder. Psychiatry Research, 172, 61-67. doi:10.1016/j.pscychresns.2008. 06.001 .

Weeks, S. J., \& Hobson, R. P. (1987). The salience of facial expression for autistic children. Journal of Child Psychology and Psychiatry, 28, 137-151. doi:10.1111/j.1469-7610.1987.tb00658.x.

Whitehouse, A. J., Durkin, K., Jaquet, E., \& Ziatas, K. (2009). Friendship, loneliness and depression in adolescents with Asperger's syndrome. Journal of Adolescence, 32, 309-322. doi: 10.1016/j.adolescence.2008.03.004.
Widen, S. C., \& Russell, J. A. (2008). Young children's understanding of other's emotions. In M. Lewis \& J. M. Haviland-Jones (Eds.), Handbook of emotions (pp. 348-363). New York: Guilford.

Willemsen-Swinkels, S. H., Bakermans-Kranenburg, M. J., Buitelaar, J. K., van Ijzendoorn, M., \& van Engeland, H. (2000). Insecure and disorganised attachment in children with a pervasive developmental disorder: relationship with social interaction and heart rate. Journal of Child Psychology and Psychiatry, 41, 759-767. doi:10.1111/ 1469-7610.00663.

Wing, L., \& Gould, J. (1979). Severe impairments of social interaction and associated abnormalities in children: epidemiology and classification. Journal of Autism and Developmental Disorders, 9, 11-29. doi:10.1007/BF01531288.

Winsler, A., Abar, B., Feder, M. A., Schunn, C. D., \& Rubio, D. A. (2007). Private speech and executive functioning among highfunctioning children with autistic spectrum disorders. Journal of Autism and Developmental Disorders, 37, 1617-1635. doi:10. 1007/s10803-006-0294-8.

Witwer, A. N., \& Lecavalier, L. (2010). Validity of comorbid psychiatric disorders in children with autism spectrum disorders. Journal of Developmental and Physical Disabilities, 22, 367-380. doi:10. 1007/s10882-010-9194-0.

Wong, T. K., Fung, P. C., Chua, S. E., \& McAlonan, G. M. (2008). Abnormal spatiotemporal processing of emotional facial expressions in childhood autism: dipole source analysis of event-related potentials. European Journal of Neuroscience, 28, 407-416. doi:10. 1111/j.1460-9568.2008.06328.x.

Yirmiya, N., \& Sigman, M. (2001). Attachment in children with autism. In J. Richer \& S. Coates (Eds.), Autism: the search for coherence (pp. 53-64). London: Jessica Kingsley Publishers.

Yirmiya, N., Kasari, C., Sigman, M., \& Mundy, P. (1989). Facial expressions of affect in autistic, mentally retarded and normal children. Journal of Child Psychology and Psychiatry, 30, 725-735. doi:10. 1111/j.1469-7610.1989.tb00785.x.

Yirmiya, N., Sigman, M. D., Kasari, C., \& Mundy, P. (1992). Empathy and cognition in high-functioning children with autism. Child Development, 63, 150-160. doi:10.1111/j.1467-8624.1992.tb03603.x.

Young, G. S., Merin, N., Rogers, S. J., \& Ozonoff, S. (2009). Gaze behavior and affect at 6 months: predicting clinical outcomes and language development in typically developing infants and infants at risk for autism. Developmental Science, 12, 798-814. doi:10.1111/j. 1467-7687.2009.00833.x.

Zeanah, C. H., Smyke, A. T., \& Dumitrescu, A. (2002). Attachment disturbances in young children. II: indiscriminate behavior and institutional care. Journal of the American Academy of Child and Adolescent Psychiatry, 41, 983-989. doi:10.1097/00004583200208000-00017.

Zelazo, P. R., \& Cunningham, W. A. (2007). Executive function: Mechanisms underlying emotion regulation. In W. A. Cunningham \& J. J. Gross (Eds.), Handbook of emotion regulation (pp. 135-158). New York: Guildford Press.

Zeman, J., Cassano, M., Perry-Parrish, C., \& Stegall, S. (2006). Emotion regulation in children and adolescents. Journal of Developmental and Behavioral Pediatrics, 27, 155-168. doi:10.1111/j.1467-8624. 1998.tb06195.x.

Zinke, K., Fries, E., Kliegel, M., Kirschbaum, C., \& Dettenborn, L. (2010). Children with high-functioning autism show a normal cortisol awakening response (CAR). Psychoneuroendocrinology, 35, 1578-1582. doi:10.1016/j.psyneuen.2010.03.009.

Zwaigenbaum, L., Bryson, S., Rogers, T., Roberts, W., Brian, J., \& Szatmari, P. (2005). Behavioral manifestations of autism in the first year of life. International Journal of Developmental Neuroscience: The Official Journal of the International Society for Developmental Neuroscience, 23, 143-152. doi:10.1111/jcpp.12328. 